This item was submitted to Loughborough's Research Repository by the author.

Items in Figshare are protected by copyright, with all rights reserved, unless otherwise indicated.

\title{
Advances in quadrupole and time-of-flight mass spectrometry for peptide MRM based translational research analysis
}

PLEASE CITE THE PUBLISHED VERSION

https://doi.org/10.1002/pmic.201500500

\section{PUBLISHER}

(c) Wiley

VERSION

AM (Accepted Manuscript)

\section{PUBLISHER STATEMENT}

This work is made available according to the conditions of the Creative Commons Attribution-NonCommercialNoDerivatives 4.0 International (CC BY-NC-ND 4.0) licence. Full details of this licence are available at: https://creativecommons.org/licenses/by-nc-nd/4.0/

\section{LICENCE}

CC BY-NC-ND 4.0

\section{REPOSITORY RECORD}

Mbasu, Richard J., Liam Heaney, Billy J. Molloy, Chris J. Hughes, Leong L. Ng, Johannes P.C. Vissers, James I. Langridge, and Donald J.L. Jones. 2019. "Advances in Quadrupole and Time-of-flight Mass Spectrometry for Peptide MRM Based Translational Research Analysis”. figshare. https://hdl.handle.net/2134/33318. 
Advances in Quadrupole and Time-of-Flight Mass Spectrometry for Peptide MRM based Translational Research Analysis

Richard J Mbasu ${ }^{1,2, \neq}$, Liam M Heaney ${ }^{2, \neq}$, Billy J Molloy ${ }^{3, \neq}$, Chris J Hughes ${ }^{3, \neq}$, Leong L Ng², Johannes PC Vissers ${ }^{3}$, James I Langridge ${ }^{3, *}$, Donald JL Jones ${ }^{1,2}$

1 Department of Cancer Studies, RKCSB, University of Leicester, Leicester, United Kingdom

2 Department of Cardiovascular Sciences and NIHR Leicester Cardiovascular Biomedical Research Unit, Glenfield Hospital, Leicester, LE3 9QP, United Kingdom

3 Waters Corporation, Wilmslow, United Kingdom

₹ these authors contributed equally to this work

* to whom correspondence should be addressed (james_langridge@waters.com)

\section{Abstract}

The application of unit resolution tandem quadrupole and high-resolution orthogonalacceleration time-of flight mass spectrometers for the quantitation and translational analysis of proteolytic peptides is described. The mass spectrometry platforms were contrasted in terms of sensitivity and linear response. Moreover, the selectivity of the platforms was investigated and the effect on quantitative precision studied. Chromatographic LC conditions, including gradient length and configuration, were investigated with respect to speed/throughput, whilst minimizing isobaric interferences, thereby providing information with regard to practical sample cohort size limitations of LC-MS for large cohort experiments. In addition to these fundamental analytical performance metrics, precision and linear dynamic range were also studied. An LC-MS configuration that encompasses the best combination of throughput and analytical accuracy for translational studies was chosen, despite the MS platforms giving similar quantitative performance, and instances were identified where alternative combinations were found to be beneficial. This configuration was utilized to demonstrate that proteolytically digested non-depleted samples from heart failure patients could be classified with good discriminative power using a subset of proteins previously suggested as candidate biomarkers for cardiovascular diseases.

\section{Significance of the study}

The understanding of disease and drug development is critical in both discovery and translational clinical studies. The differentiation and validation of the integral biological components are however technologically challenging. The results from this study demonstrate clear technological advances that will assist and accelerate validation of early phase discoveries. 


\section{Introduction}

Bioanalytical proteomics workflows originally consisted of the qualitative profiling of two or more samples/groups using gel-based separation techniques with some type of optical read-out $[1,2]$. The benefits of mass spectrometry were readily recognised with the development of in-gel digestion and peptide extraction techniques in combination with peptide mass fingerprint MALDI time-of-flight [3] and nanoelectrospray tandem mass spectrometry [4] making protein identification more routine and main stream. The following advances included the use of one and two-dimensional nanoscale LC chromatography, originally developed by the chromatographic community but embraced and brought forward by the proteomics community because of increased method sensitivity, which afforded the analysis of more complex samples in an automated fashion. Meanwhile, continued high-resolution mass spectrometer developments, such as modes of acquisition, resolution, analyzer types and combinations, speed and sensitivity, lead to the identification of more proteins and putative disease markers at increasingly faster identification rates. The more recent developments include the incorporation of orthogonal separation techniques within instruments designs, as for example, ionic gas phase based ion-mobility $[5,6]$.

Quantitation in discovery LC-MS based proteomics experiments is typically conducted by either labelled or label-free methods. Labels can be incorporated metabolically or by using chemical techniques $[7,8]$. In both instances, a known or predictable peptide mass shift is introduced, affording the differential quantitation of peptides and their parent proteins. The read-out can be either at the precursor, including techniques such as ICAT, SILAC, dimethyl-labelling [9-11], or at the product ion level, of which iTRAQ and TMT labelling are representatives $[12,13]$. The former methods limit the experimental design in terms of the number of samples that can be compared, but arguably provide the best precision, whereas the latter methods provide a higher degree of multiplexing but at the cost of reduced dynamic quantitation range. Label-free methods have gained great popularity over the last decade with ion abundance based methods believed to provide the best accuracy and precision [14-16]. Appealing benefits of these methods are the increased dynamic range and the freedom in experimental design compared to quantitative labelled LC-MS methods. An additional benefit is that the amount of the identified proteins can be estimated without the use of stable isotope labelled standards [17]. Attention has to be given however to experimental variation as this is carried through and affects the total observed error.

Targeted LC-MS based assays are increasingly applied in the post-discovery proteomics area with emphasis on validation, the first of many phases in translational analyses, or in studies that are aimed at gaining the understanding of biological systems, drug development and treatment. Context is driving current proteomics experiments, thereby also driving the development of LC-MS acquisition methods that can provide both qualitative and quantitative information in a single experiment. With the increased availability of spectral libraries and public discovery results repositories $[18,19]$, the identification of disease related or pathway associated proteins is not seen, or at least strongly reduced, as a prerequisite for larger scale, confirmatory type studies. Moreover, targeted, multiplexed assays are believed to be a viable alternative for antibody based assays because of improved specificity. Both tandem quadrupole and high-resolution mass spectrometers are applied for these types of studies [20-23]. Multiple/selected reaction monitoring (MRM/SRM) based assays are especially believed to have the potential to afford protein quantitation with the reproducibility and throughput required 
in order to improve biomarker acceptance. These types of experiments are however technologically challenged since they require analyzing a large number of samples with high-throughput, but also require high sensitivity, high resolution, large dynamic range and excellent selectivity at the same time. Here, tandem quadrupole and high-resolution mass spectrometers are systematically compared to demonstrate and contrast the application of these analyzer types and how they could be operated for targeted protein quantitation experiments. In addition, two different types of LC interfaces have been evaluated with regard to their contribution to throughput/robustness vs. sensitivity. A small cohort of heart failure disease patient blood samples was analyzed. Heart failure (HF) poses a significant burden on healthcare systems around the world. The causes of HF are disparate and can involve interplay between several biological systems [24]. An examination of the expression of thirteen proteins that populate biological pathways intertwined with HF will test the feasibility and potential use of LC-MRM-MS for translational analysis.

\section{Experimental Conditions}

\section{Blood sample collection and plasma extraction}

Human blood samples were collected from a cohort of twenty healthy donors, twenty heart failure with preserved ejection fraction (HFPEF) patients, and twenty heart failure with reduced ejection fraction (HFREF) patients, following informed consent. All HFPEF patients had an ejection fraction of $\geq 50 \%$ and HFREF patients had an ejection fraction $\leq 40 \%$. A volume of $20 \mathrm{~mL}$ of blood was collected in a Sterilin tube containing $330 \mu \mathrm{L}$ of Trasylol ( $=3000$ Kallikrein Inhibitor Units) and $80 \mu \mathrm{L}$ of $1 \mathrm{M}$ EDTA per $20 \mathrm{~mL}$ of blood. The blood was mixed before centrifugation at $15000 \mathrm{~g}$ at $4{ }^{\circ} \mathrm{C}$ for $30 \mathrm{~min}$. The plasma layer was separated from the buffy layer and red blood cells, and stored at $-80^{\circ} \mathrm{C}$.

\section{Protein digestion protocols}

Twenty microliters of undepleted human EDTA test sample plasma (Sigma-Aldrich, St. Louis, MO) for the comparative configuration part of the study was diluted with $80 \mu \mathrm{L}$ of $50 \mathrm{mM}$ ammonium bicarbonate solution and denatured in the presence of $10 \mu \mathrm{L}$ of $1 \%$ RapiGest (Waters Corporation, Milford, MA) detergent solution at $80{ }^{\circ} \mathrm{C}$ for $45 \mathrm{~min}$. The plasma proteins were reduced in the presence of $5 \mu \mathrm{L}$ of $100 \mathrm{mM}$ dithiothreitol at $60{ }^{\circ} \mathrm{C}$ for $30 \mathrm{~min}$. and alkylated in the dark in the presence of $6 \mu \mathrm{L}$ of $200 \mathrm{mM}$ iodoacetamide at ambient temperature for $30 \mathrm{~min}$. Proteolytic digestion was initiated by adding $40 \mu \mathrm{L}$ of $1 \mu \mathrm{g} / \mu \mathrm{L}$ sequencing grade, modified trypsin (Promega, Madison, MI) and incubated overnight at $37^{\circ} \mathrm{C}$. Breakdown of the acid-labile detergent was achieved in the presence of $1 \%$ TFA at $37^{\circ} \mathrm{C}$ for $45 \mathrm{~min}$. The peptide solutions were centrifuged at $13,000 \mathrm{rpm}$ for $10 \mathrm{~min}$, and the supernatants collected.

Patient and donor plasma samples were digested as previously described with minor modifications [25]. RapiGest solution was then added to the samples to give a $0.1 \%$ final concentration and incubated at $80^{\circ} \mathrm{C}$ for $45 \mathrm{~min}$. The samples were then reduced with $100 \mathrm{mM}$ aqueous DTT solution added to give a final concentration of $5 \mathrm{mM}$ prior to incubation at $60^{\circ} \mathrm{C}$ for $30 \mathrm{~min}$. A $200 \mathrm{mM}$ IAA solution was added to the samples to give a final concentration of $10 \mathrm{mM}$ before incubation in the dark at room temperature for 30 min. A trypsin solution of $1 \mu \mathrm{g} / \mu \mathrm{L}$ was added to the sample in a $1: 50 \mathrm{w} / \mathrm{w}$ ratio and incubated at $37^{\circ} \mathrm{C}$ overnight. Digestion was concluded, and RapiGest cleaved, with the addition of neat formic acid to the sample to give a final concentration of $0.5 \%$. The plasma samples were centrifuged at $13,000 \mathrm{rpm}$ for $10 \mathrm{~min}$ to remove insoluble material, and the supernatants collected. 


\section{LC configurations}

1D nanoscale LC separation of tryptic peptides was performed with a Acquity M-class system (Waters Corporation), equipped with a Symmetry C18 $5 \mu \mathrm{m}, 2 \mathrm{~cm} \times 180 \mu \mathrm{m}$ precolumn and an HSS T3 C18 $1.8 \mu \mathrm{m}, 25 \mathrm{~cm} \times 75 \mu \mathrm{m}$ analytical RP column (Waters Corporation). The samples were transferred with aqueous $0.1 \%(\mathrm{v} / \mathrm{v})$ formic acid to the precolumn at a flow rate of $5 \mu \mathrm{L} / \mathrm{min}$ for $3 \mathrm{~min}$. Mobile phase $A$ was water containing $0.1 \%(\mathrm{v} / \mathrm{v})$ formic acid, whilst mobile phase B was acetonitrile containing $0.1 \%(\mathrm{v} / \mathrm{v})$ formic acid. After desalting and preconcentration, the peptides were eluted from the precolumn to the analytical column and separated with a gradient of $3-40 \%$ mobile phase B over $90 \mathrm{~min}$ at a flow rate of $300 \mathrm{~nL} / \mathrm{min}$, followed by a 2 min column rinse with $85 \%$ of mobile phase $\mathrm{B}$. The columns were re-equilibrated at initial conditions for 20 min. The analytical column temperature was maintained at $35^{\circ} \mathrm{C}$.

Additional, higher throughput experiments were performed with $150 \mu \mathrm{m} \times 100 \mathrm{~mm}$ ionKey/MS micro-fluidics packed with BEH C18 $1.7 \mu \mathrm{m}$ [26]. Gradient conditions were from $3-40 \%$ B gradient over $45 \mathrm{~min}$ at a flow rate of $1 \mu \mathrm{L} / \mathrm{min}$, followed by a $6 \mathrm{~min}$ column wash with $85 \%$ of mobile phase B. The columns were re-equilibrated at initial conditions for $9 \mathrm{~min}$. The analytical column temperature was maintained at ambient temperature. Samples were injected/loaded directly on-column or using a precolumn configuration. In this instance, the precolumn was $5 \mathrm{~cm} \times 300 \mu \mathrm{m}$ id, packed with $5 \mu \mathrm{m}$ Symmetry $\mathrm{C} 18$ and samples loaded with a flow rate of $15 \mu \mathrm{L} / \mathrm{min}$ for $1 \mathrm{~min}$. Faster reversed phase gradient separation, both nanoscale LC and micro-fluidics based, were explored but not considered for detailed analysis as (isobaric) interferences or detection issues were readily observed, as exemplified in Supplementary Figure 1, hampering more detailed comparative configuration analysis.

MS configurations

Multiple Reaction Monitoring (MRM) analysis was performed using two tandem quadrupole mass spectrometers, Xevo TQ-S and Xevo-TQ-S micro, and two hybrid quadrupole orthogonal acceleration time-of-flight platforms, Xevo G2-XS Q-ToF and Synapt G2-Si (Waters Corporation, Wilmslow, United Kingdom). The Synapt G2-Si instrument is equipped with a travelling wave ion, tri-wave ion guide, which comprises two stacked ring collision induced dissociation (CID) regions, separated by a travelling wave guide that can be used for ion mobility separation. This configuration is described in detail elsewhere $[6,27]$. All experiments were performed in positive electrospray ionisation (ESI) mode. The ion source block temperatures and capillary voltages were kept constant for all instruments and set to $70{ }^{\circ} \mathrm{C}$ and $3.2 \mathrm{kV}$. Micro-fluidics interfaced experiments were typically conducted with a slightly increased capillary voltage of 3.6 $\mathrm{kV}$. The $\mathrm{N}_{2}$ cone gas flow and nanoflow gas pressure were $35 \mathrm{~L} / \mathrm{h}$ and 0.2 bar, respectively, whereas the Ar collision gas flow equalled $2 \mathrm{~mL} / \mathrm{min}$. The quadrupole and time-of-flight analyzers were externally calibrated with NaCsI mixtures from $\mathrm{m} / \mathrm{z} 50$ to 1990.

A number of instrument and analyzer specific parameters, as well as the acquisition types, used in this study are presented in Table 1. Endogenous and stable isotope labelled (SIL) peptides were targeted by at least three transitions with a minimum of 10 data points over a chromatographic peak. Tandem quadrupole dwell and interscan delay times were automatically calculated by the operating software based on a minimum number of data points specified at half height across a chromatographic peak. Collision energies were set at fixed values for the tandem quadrupole instruments and ramped for 
the time-of-flight instrument. In addition, for the time-of-flight based MRM acquisitions, integration and interscan delay times were manually set. Collision energies were ramped and initially calculated using the following regression equation: 0.034 times $m / z+3.314$ $\mathrm{eV}$, and further optimized by CID fragmentation evaluation obtained by repeat injections of SIL peptides in the absence of matrix. The MRM transitions for both instrument types are listed in Supplementary Table 1.

\section{Experimental designs}

Fifteen stable isotope labelled (SIL) peptides (PepScan, Lelystad, Netherlands), representing putative blood-based cardiovascular disease protein biomarkers spanning over five orders of dynamic concentration range [28], were initially spiked as a dilution series from $6.25 \mathrm{amol}$ to $12.5 \mathrm{fmol}$ on-column, in tryptic digested EDTA human plasma. The SIL peptides and associated proteins of interest are shown in Table 2, including normal plasma protein and molar peptide concentration values [29]. In total, considering all LC-MS configurations and column/interface formats, 108 LC-MS experiments were conducted. Extended dynamic range experiments were conducted with one of the SIL peptides at spike levels ranging from 7.5 amol to $1.5 \mathrm{pmol}$, in tryptic digested human plasma as well.

The healthy donor, HFPEF and HFREF plasma samples were spiked post-digestion at four individual different levels of $0.25,0.5,2$ and $10 \mathrm{fmol}$ each with the same fifteen SIL peptides, analyzed separately, providing multiple, user selectable quantitation levels and surrogate technical replicates, mounting to a total of 240 LC-MS experiments ( $~ 10$ days of measurement time).

\section{Sulfadimethoxine base sensitivity analysis}

Base sensitivity analysis were conducted with Xevo TQ-S micro and Xevo G2-XS QToF platforms, both operated in positive ion mode ESI and interfaced to an Acquity $\mathrm{H}$ class system (Waters Corporation), and sulfadimethoxine (Sigma-Adrich) as the test analyte. The source temperature was maintained at $150{ }^{\circ} \mathrm{C}$, the desolvation temperature at $550{ }^{\circ} \mathrm{C}$, the desolvation gas flow at $1000 \mathrm{~L} / \mathrm{h}$, and the capillary voltage set at $4 \mathrm{kV}$. Mobile phase $A$ was aqueous $0.1 \%(\mathrm{v} / \mathrm{v})$ formic acid/0.05\% ( $/ \mathrm{v})$ ammonia solution, and mobile phase $B$ acetonitrile containing $0.1 \%(\mathrm{v} / \mathrm{v})$ formic acid. The column was $2.1 \times 50$ $\mathrm{mm}$ packed with $\mathrm{BEH} 1.7 \mu \mathrm{m}$ stationary phase (Waters Corporation), operated at 0.8 $\mathrm{mL} / \mathrm{min}$, and maintained at $40^{\circ} \mathrm{C}$.

\section{Informatics}

Tandem quadrupole and high resolution Q-ToF LC-MS peptide MRM data were quantified with either TargetLynx (Waters Corporation) or Skyline [30], and analyzed and visualized with Spotfire v6.0.0 (TIBCO software, Boston, MA). All statistical analyses were conducted with SIMCA (v14, MKS Umetrics AB, Umeå, Sweden) or IBM SPSS statistics v22 (IBM Corporation, Armonk, NY).

Orthogonal partial least squares-discriminant analyses (OPLS-DA) were performed on the candidate peptides as a ratio to their labelled standard and all data Pareto scaled. Sample runs that deviated significantly from the Hotelling's $T^{2} 95 \%$ confidence interval were excluded and the model refitted. Peptides considered as contributing to the supervised separation of groupings were identified by consultation of the accompanying S-plot. OPLS-DA models were produced for control subjects vs. those with heart failure, and for heart failure with reduced ejection fracture vs. preserved ejection fraction. 
Pair-wise comparisons for identified peptides of interest were performed by the Mann Whitney $U$ test for independent samples. Logistic regressions were performed to calculate the probabilities of heart failure prediction for each individual peptide of interest, and as a combination of all these peptides. Receiver operator characteristic curves were produced using these probabilities and the areas under the curve were calculated. All tests with a two-tailed $p$ value of $<0.05$ were deemed as statistically significant.

\section{Results and discussion}

Biomarker discovery and validation are the first steps in understanding disease and finding surrogate markers for drug development. Validation is challenged since it requires the analysis of a large number of samples with high-throughput, but also with high sensitivity, reproducibility, robustness, accuracy and precision over a large dynamic range. Targeted LC-MS based assays have been shown previously to afford protein quantitation with the reproducibility and throughput required in order to improve biomarker acceptance [31]. MRM based assays on tandem quadrupole instruments have been the primary technology used, but more recently higher mass resolution system and those incorporating and hybridising ion mobility with high resolution mass spectrometry have been described.

The Clinical Proteomic Tumor Analysis Consortium (CPTAC) designed a series of interrelated studies to assess the reproducibility and quantitative characteristics of tandem/triple quadrupole based MRM assays [32-35], as well as developing reference materials, software tools, and guidelines for data sharing. Tandem and triple quadrupole mass spectrometers were applied in these studies since they are the quantitation 'gold standard', providing a high speed multiplexing capability compared to other analyzer types, a large linear dynamic range of quantitation, and have good sensitivity, signal-tonoise and specificity. Despite this, tandem quadrupole based MRM has been challenged and criticized from both a biological and technical perspective, and mass spectrometry based alternatives, using high-resolution mass analyzers, explored [23,36-39]. Notwithstanding these challenges, tandem/triple quadrupole mass spectrometers have been successfully applied for the quantitative analysis of proteins. As an example, Carr et al. [40] reported on the efficient quantitation of low-abundance plasma proteins, representing an 800-plex MRM based LC-MS assay, run in a single analysis, comprising 2400 transitions with retention time scheduling to monitor 400 unlabeled and heavy labelled peptide pairs.

Analytical performance and ion transmission

One of the evaluated tandem quadrupole MS platforms in this study was also used in the CPTAC studies [32-35] and numerous other biomarker studies including the previously mentioned highly multiplexed study [40]. This platform will be used as the base for the comparative experiment, with emphasis on sensitivity, throughput/speed, selectivity, precision and accuracy for the quantitation of peptides and proteins. From a theoretical perspective, a number of parameters need to be considered when comparing tandem mass spectrometry geometries. The first mass analyzer of all platforms comprises a quadrupole ion guide. The transmission of these devices typically ranges from 50 to $80 \%$ at 0.7 Da FWHM resolution [41]. Within a tandem quadrupole configuration, the overall transmission would equal the product of the transmission of the individual analysers. In a hybrid quadrupole orthogonal acceleration time-of-flight mass spectrometer, the transmission across a narrow $\mathrm{m} / \mathrm{z}$ range can approach $100 \%$ if 
the pusher is synchronized with the output from the collision cell [42]. An approach has previously been described that can maximise the duty cycle of the orthogonal acceleration time-of-flight (oa-ToF) to close to $100 \%$ across the $\mathrm{m} / \mathrm{z}$ range using the synchronization of the ion mobility separation stage with the pusher of the oa-ToF [43]. Thus, dependent upon the configuration, an oa-ToF analyzer is close to the transmission of a quadrupole ion guide operated at unit resolution. However, compounding duty cycle are interscan delay times and the number of measured transitions. Quadrupole interscan delay times can be as small as $1 \mathrm{~ms}$, not noticeably affecting transmission, whereas currently oa-ToF interscan delay times are around 5-15 ms, resulting in lower duty cycle at higher acquisition rates.

In terms of absolute sensitivity, in practice, tandem/triple quadrupole and (hybrid) oa-ToF performances can be found to be comparable. For example, for a single transition for the analysis of sulfadimethoxine the lower limits of detection (LLOD) and quantitation (LLOQ) for a tandem quadrupole (Xevo TQ-S micro) and an oa-ToF (Xevo G2-XS QTof) platform were both found to be equal to 5 and $10 \mu \mathrm{g}$ on-column. Shown in Supplementary Figure 2 are the MRM chromatograms for the transition(s) of sulfadimethoxine on both MS platforms, illustrating that the base performance/sensitivity and ion transmission for the analysis of a single compound in isolation are almost identical, under the same experimental conditions. The next paragraphs will demonstrate how the evaluated geometries compare for the multi-analyte MRM analysis of endogenous and SIL peptides spiked in undepleted digested plasma matrix and that the single analyte observations also hold for multi-analyte experiments.

\section{Transition selection and optimization}

The collision cells used in all evaluated MS geometries utilize similar low energy CID fragmentation characteristics. Shown in Figure 1, as an example, are the full scan MS/MS spectra for one of the SIL peptides, namely FPEVDVLTK- ${ }^{13} C_{6}{ }^{15} N_{2}$. The top (A) pane illustrates a tandem/triple quadrupole MS/MS spectrum, the middle (B) pane an oa-ToF equivalent, and the bottom (C) pane an enhanced duty cycle (EDC) oa-ToF full scan spectrum. As can be noted, the profiles of the tandem quadrupole and oa-ToF MS/MS spectra share great similarity, suggesting that transitions can be derived from oa-ToF based discovery experiments and translated to tandem MS geometry independent MRM transitions [44]. Also shown is that the EDC oa-ToF MS/MS spectrum, centering at $m / z 682.4$, is promoting over a relative wide $m / z$ range of a few hundred $T h$ wide across the product ion range of interest, thereby somewhat skewing the relative abundances of the product ions and their associated ratios, but significantly increasing sensitivity. Maximum duty cycle is retained in this way of operating EDC oa-ToF MRM acquisitions since only a single $m / z$ value is synchronised. The spectra shown in panels $B$ and $C$ of Figure 1 have been scaled to the $m / z 682.4$ product ion intensity values to afford direct comparison, indicating a gain in signal of approximately five for this particular 'transition'.

Fifteen peptides, representing thirteen proteins were selected from the study by Domanski et al. [28], covering more than five orders of plasma protein concentration dynamic range. Selection rules taken into consideration were concentration, amino acid composition and sequence length. The fifteen SIL peptide equivalents listed in Table 1 were pooled at equimolar levels and analyzed by both data independent analysis (DIA; $\mathrm{MS}^{\mathrm{E}}$-style) $[45,46]$ and precursor isolated MS/MS experiments in the absence of matrix to examine fragmentation behaviour and product ion distribution. Only $y^{\prime \prime}$ fragment ions were considered and the CID collision energies and ramps optimized for maximum 
product ion intensity distribution and circumventing over or under fragmentation using the collision energy regression rules described in the section Experimental Conditions as the initial collision energy values. A minimum of three transitions/product ions per peptide were selected, one peptide excluded. The selected precursor and product ion target masses, constituting the MRM transitions, are overviewed in Supplementary Table 1. The endogenous target masses were determined by calculation. EDC $m / z$ selection was based upon the relative product ion intensity (abundance) of a fragment $m / z$ value within the region of interest (precursor $m / z<E D C m / z<y \max m / z$ ). In practice this is close to the center of the $\mathrm{m} / \mathrm{z}$ range, obtained from either an experimental DIA or MS/MS product ion spectrum.

Technical and experimental variation

Several sources contribute to assay variation, including technical, experimental, and biological variation (sampling, sample preparation (solid phase extraction, digestion, pipetting, LC-MS, etc.). The variation, precision and confidence level are significant factors in determining that a given study has appropriate power and are critical when designing a translational biomarker study. The imprecision, bias, and total allowable error, calculated from data on within-subject and between-subject biologic variation for clinical assays, including plasma proteins, have been populated in a database $[47,48]$, and recently updated [47]. Accessing the biological protein plasma concentration variation of a population and the individual component and summed technical experimental variation by means of LC-MS is beyond the scope of this study; however, variation should be considered when developing and specifying quality requirements in relation to the size of the cohort to be studied. Table 3 summarizes the biological variation of a number of the proteins of which the peptides have been examined in this study as determined by accepted clinical assays. The variation is greatly protein dependent, which will determine the consideration of LC-MS as an alternative and viable technology, for example where immunoassays fail [49], as well as cohort/sample size [31]. As an example of technical variation LC-MS tandem quadrupole MRM precision was assessed to provide an appreciation of the application of LC-MS in translational studies. More extensive experimental variation study results are published in more detail elsewhere [50], including digestion [51-53], which is widely quoted and seen as a major source of variation. Three SIL peptides were spiked in fifty independent, undepleted, tryptic digested plasma samples and the absolute and relative transition abundances measured. The results shown in the top (A) pane of Figure 2 illustrate the raw summed abundances are sample dependent and different trends can be observed for the three peptides of interest. The latter can be explained by the fact that the (biological) background will vary per unit (chromatographic) time as the matrices are different for every sample but would mimic the effects observed in a larger cohort study. The left bottom (B) pane summarizes the result in box-and-whisker format with uncorrected CV values ranging from about 10 to $30 \%$. The middle bottom pane (C) illustrates the consistency of the relative abundances of the transitions (intensity of the most abundant transition/intensity sum of all transitions). This characterizes the magnitude of internal standard correction, in terms of reducing CV values from raw to relative values, and reduces the CV values by a factor of two to five. Normally, this would be achieved by contrasting the abundances of the endogenous peptides of interest with those on its SIL counterpart and assessed with informatics tools such as m-prophet [54] or AuDIT [55]. The bottom right (D) pane results illustrate retention time reproducibility numbers, which was on average close to $0.5 \% \mathrm{CV}$. 
Throughput and speed of analysis

The fastest gradient separations possible were employed without introducing isobaric interferences for the fifteen SIL peptides monitored for both LC platforms. As the microfluidics interface is operated at a higher flow-rate, and the number of connectors and connection lines reduced compared to a typical nanoscale LC set-up, system volumes are more quickly 'swiped', providing reduced gradient delivery delays and faster column conditioning. Moreover, extra-column volumes will be less critical at higher flow-rates. Typical nanoscale LC and micro-fluidics tandem quadrupole MRM chromatograms for 125 amol SIL peptides injected on-column are shown in Supplementary Figure 3, illustrating an average increase in speed of analysis of 1.9 for $150 \mu \mathrm{m}$ inner diameter (id) microfluidics vs. $75 \mu \mathrm{m}$ id nanoscale LC tryptic peptide separations at nearly identical linear mobile phase velocities. The complete experimental injection-to-injection cycle times were 1 and $2 \mathrm{~h}$ for the micro-fluidics and nanoscale LC based separations, providing a 2fold increase in throughput for the micro-fluidics experiments. Average peak widths at half-height $W_{0.5}$ were 0.07 and 0.12 min, respectively, mounting to similar peak capacity approximations of 320 and 375, assuming that the chromatographic separations spaces were 45 and 90 min. Retention time reproducibility (data not shown) was in both cases better than $1 \%$.

Quantitative comparison of platforms and column geometries

The linear response and the peak-to-peak signal-to-noise $(S / N)$ at a given concentration level were determined and the lower limit of detection estimated for a dilution series of the fifteen SIL peptides, representing thirteen proteins, spiked into undepleted, tryptic digested plasma. The injected plasma digest on-column amount, assuming a normal total protein concentration of $70 \mathrm{~g} / \mathrm{L}$, equalled $140 \mathrm{ng} . \mathrm{S} / \mathrm{N}$ values were determined at $12.5 \mathrm{amol}$ injected on-column for the $75 \mu \mathrm{m}$ id nanoscale LC based experiments and at the 125 amol level for the $150 \mu \mathrm{m}$ id micro-fluidics LC-MS separations, respectively. The MS response and assay sensitivities were initially tested from $6.25 \mathrm{amol}$ to $12.5 \mathrm{fmol}$ for the nanoscale LC based experiments and from 62.5 amol to $12.5 \mathrm{fmol}$ for the micro-fluidics separations, with the tested dynamic range extended for a subset of configurations, including additional technical LC-MS replicates, as described below.

The results are summarized in Table 4 and Supplementary Table 2. Within the tested range, exceeding three orders of concentration dynamic range, all mass spectrometers demonstrated $1 / x$ weighted linear behaviour with $r^{2}$ regression correlation coefficient values of 0.9909 or greater for all SIL peptides. Similarly, the $S / N$ values measured at the $12.5 \mathrm{amol}$ and $125 \mathrm{amol}$ spike level were found to be comparable for the majority of the SIL peptides measured with all LC-MS configurations, ranging from 2 to 30 for the 75 $\mu \mathrm{m}$ id nanoscale LC setup, and 2 to 100 for the $150 \mu \mathrm{m}$ id micro-fluidics configuration, respectively. The median and average lower limit of detection (LLOD) values, across all MS platforms equalled 5 and 8 amol for the $75 \mu \mathrm{m}$ id nanoscale LC experiments, and 20 and $39 \mathrm{amol}$ for the 150 id micro-fluidics LC-MS. The experiment also afforded calculation of the concentration of some of the endogenous peptides that were within the measured dynamic range. The results shown in Table 5 overview the determined concentrations of the endogenous peptides (proteins) for the $75 \mu \mathrm{m}$ id nanoscale LC based experiments and Supplementary Table 3 for the $150 \mu \mathrm{m}$ id micro-fluidics LC-MS separations, respectively. The concentration and coefficient of variation (CV) were calculated for each individual SIL spike-level, representing a multi-level single point 
average and error estimate. The average CV values, across all MS platforms as well, for the nanoscale LC and micro-fluidics experiments were found to be equal to $8.6 \pm 3.5 \%$ and $10.3 \pm 4.7 \%$, respectively. The MRM data of the LC platform/configuration comparative part of the study are provided in 'Supplementary Information - LC-MS Configuration Comparison'.

\section{Extended dynamic range experiments}

Despite quite similar and impressive levels of analytical performance, the best overall/combined performance in terms of CV precision and throughput, see previous sections, was obtained with the $150 \mu \mathrm{m}$ id micro-fluidics interface in combination with one of the tandem quadrupole mass spectrometers. The dynamic range of the assay was extended and the detection of the lower abundant target peptides improved by using a trap-column based LC configuration of which the details are provided in the Experimental section. This column configuration allows for the loading of five-fold more protein plasma digest without affecting the chromatographic performance of the system (data not shown) and afforded the detection of fourteen of the fifteen target peptides/proteins in undepleted plasma. Linear response was observed for LGPLVEQGR- ${ }^{13} \mathrm{C}_{6}{ }^{15} \mathrm{~N}_{4}$ from 15 amol to $1.5 \mathrm{pmol}$ injected on-column in the presence of matrix, representing five orders of magnitude of linear LC-MS response, as illustrated in Supplementary Figure 4, with a median $\%$ CV value, for the individual SIL standard levels, of $5.5 \%$, and a $r^{2}$ regression correlation coefficient of 0.9842 .

Mobility enabled MRM methods

IM enabled oa-ToF MRM acquisition modes can provide either increased selectivity or sensitivity. These modes could be useful for lower level peptides that challenge assay specificity and are briefly described with example results presented. With the mobility enabled oa-ToF platform, the collision cell/mobility separation region comprises three stacked ring ion guide devices placed in series (tri-wave). The first region can be used to either trap ions or conduct CID fragmentation. Within the second region, the ions, either precursor or product ions, dependent on the use of the trap region, undergo mobility separation. In the third region, the ions are either transferred to the oa-ToF analyzer or CID fragmented. The device has been described in detail elsewhere $[26,56,57]$, as well as alternative uses of stacked ring ion guides, including electron transfer dissociation [58] and top-down type studies [59]. The two cases described here are graphically summarized in Figure 3. The top (A) pane illustrates a case where ion mobility separation is achieved in the second region and CID conducted in the third region, aiming at achieving additional assay selectivity. The bottom (B) pane demonstrates ion mobility separation at the product ion level which is aimed at increasing sensitivity across the complete $\mathrm{m} / \mathrm{z}$ fragment ion range by optimizing the duty cycle of the instrument. In short, product ions are trapped within the first region of the tri-wave device and gated into the high-pressure ion mobility region where they are separated according to their gas phase mobility, which is predominantly determined by mass, charge, size, and shape. As a result, fragment ions of the same mobility exit the cell as a series of compact packets. Hence, by synchronizing the pusher pulse that accelerates the fragment ions into the oa-ToF mass analyzer with the arrival of product ions into the pusher region, fragment ions are sequentially injected into the ToF analyzer with greatly enhanced duty cycle ( $\sim 85 \%$ ) across the mass scale [43].

The benefit of the latter case is illustrated in Figure 4, showing typical sub 100 amol on-column results obtained with oa-ToF MRM data collected in normal MRM mode using 
EDC in the top (A) pane and with product ion IM separation in the bottom (B) pane. Data were normalized to the endogenous level to account for any experimental LC-MS variation and collected in so-called isotope stripping mode, whereby only isotopic information is stored for a pre-defined set of product ions, reducing file size significantly without losing quantitative information. As can be seen, the mobility enabled method provided better sensitivity. The effect of EDC can be noted as illustrated by the relative high intensity of the high mass vs. the low mass product ions, which was aimed at sacrificing the low $\mathrm{m} / \mathrm{z}$ product ion region nearly completely by promoting the oa-ToF duty cycle for the more specific high $m / z$ product ions. An example of the former mentioned IM enabled oa-ToF MRM method, where additional precursor and product ion separation can be achieved of co-isolated peptides that differ in ion mobility characteristic or CCS value, prior to CID in the transfer region of the tri-wave mobility/collision cell, is shown in Figure 5. The application of these highly selective oaToF modes of acquisition for the quantitation of peptides and proteins will be published in a separate communication.

\section{Application results}

Heart failure represents a heterogeneous clinical population for which biomarkers are sparse. The aetiology of the disease also means that the phenotypic changes are likely to be multifactorial. As a proof of principle and test of overall sensitivity to classify this heterogeneous disease, twenty healthy controls, twenty patients with HFPEF and twenty heart failure patients with HFREF were analyzed. For this particular application, the micro-fluidics interface, equipped with a pre-column, was used in combination with one of the tandem quadrupole mass spectrometers, as it provided the best combination of throughput, loadability, sensitivity, precision and linearity. The micro-fluidics gradient conditions were adjusted to the previously described experiments, namely from 2 to $30 \% \mathrm{~B}$ in $45 \mathrm{~min}$ at $35^{\circ} \mathrm{C}$, to increase chromatographic resolution. Multivariate analysis of proteins showed that patient samples could be classified using OPLS-DA, using the data and results obtained from one of the SIL spike level $(10 \mathrm{fmol})$ experiments, as illustrated by the scores distribution/summary in Figure 6. Partial separation of healthy controls and HF (combined HFPEF and HFREF) can be observed. Fit $\left(R^{2}\right)$ and prediction $\left(\mathrm{Q}^{2}\right)$ values of 0.52 and 0.38 were obtained, respectively, for the developed model. The three proteins contributing mostly to the separation, as identified by analyzing the loadings distributions, covariance vs. correlation, were Apolipoprotein A-1 (APOA), Plasma protease $\mathrm{C} 1$ inhibitor (SERPING1) and C-reactive protein (CRP). Univariate analysis of these three proteins showed significant changes in levels between the groups, as summarized in Figure $7 \mathrm{~A}-\mathrm{C}$. Good discriminant power was obtained by combining these protein surrogate peptides, with an area under the receiver operating characteristic curve of 0.937 obtained as illustrated in Figure 7D. Previous work demonstrated that ApoA1 is potentially protective in $\mathrm{HF}$, so the lower observed levels in the HF group would be consistent [60]. CRP is well known to increase with heart failure [61], and plasma protease C1 inhibitor may well be indicative of remodelling, which is a clear pathophysiological mechanism in heart failure. Distinct separation between all three groups, namely control, HFPEF and HFREF, was not obtained with the selected subset of peptides, however, a partial separation model could be developed for HFREF and HFPEF, see Supplementary Figure 5 . These results suggest that a classification model can be achieved with a multi-analyte LC-MRM-MS assay, using tandem quadrupole mass spectrometry combined with micro-fluidics, and a subset of three proteins from the thirteen proteins examined. Improvements to the model would necessitate a larger 
cohort of samples or the use of other peptides/proteins, which was outside the scope of this study. However, the strength of the model and the biological processes identified as contributing to the model indicate that this approach may yield successful opportunities for biomarker research. The MRM data of the biological part of the study are provided in 'Supplementary Information - Application Results'.

\section{Conclusions}

LC-MRM-MS has been adopted and widely applied in translational biomarker studies due to the inherent speed of developing a multiplexed assay that can be deployed with relatively high sensitivity and throughput. In this study, building upon previous studies, the effect of both the LC scale and the choice of MS platform has been investigated. In biomarker discovery, many performance studies have been conducted using extensively high performance LC-MS systems. However, the technical and performance challenges in biomarker translation studies are different and require a robust and reliable platform, with good quantitative precision that can analyse much larger cohorts of samples. The results presented show that with regard to the LC component, despite nanoscale LC being the predominant separation technology in quantitative protein biomarker studies, it was found that a larger $150 \mu \mathrm{m}$ inner diameter scale micro-fluidic based system has the required sensitivity and quantitative performance, combined with throughput characteristics required for quantitative translational studies.

In the case of the MS platform, the use of higher resolution systems can have significant benefits in the targeted analysis of biomarkers in biological matrices. The elevated resolution can often be translated in increased specificity and therefore a more reliable measure of a peptide and hence proteins abundance. In this study, looking at a range of peptides in undepleted human plasma, the sensitivity was found to be very comparable between the modern tandem quadrupole and the quadrupole time-of-flight systems, but the combination of a high sensitivity tandem quadrupole with a microfluidic inlet provided the best coefficient of variation, throughput and sensitivity/signalto-noise. It may be surprising, in some regards, that the elevated resolution of the second mass analyser of the time-of-flight systems does not translate to into improved quantitative performance, but in this study the peptides, even at levels close to their lower limit of quantitation provided a linear response with all MS platforms.

The preferred instrument configuration was used for the analysis of the selected peptides, and hence proteins, originating from heart failure disease patients, and compared to matched control samples. This preliminary study was designed to test the overall sensitivity and to classify this heterogeneous disease, resulting in separation of the two disease groups from the control group and partial separation of the two disease phenotypes. The multiplex assay will be further tested on a larger cohort of heart failure patients to test the classification. This study has shown that the applied LC-MS platform demonstrates suitable throughput and sensitivity to accommodate analysis of much larger cohorts that are typical in cardiovascular biomarker discovery ( $>1000$ patient samples). Moreover, what is particularly attractive about this configuration is that the step from initial discovery to verification of initial candidates can be rapidly executed using a targeted MS approach rather than an alternative such as immunoassay or western blot which are potentially more expensive, less specific and consume more sample than the methods described here. Thus, the transition from discovery to validation is greatly accelerated. Additionally, it is plausible that further candidates could 
be integrated with relative ease, providing future flexibility and with little detriment to throughput.

LC-MS technology continues to mature and the current technology has the required analytical performance to make large-scale biomarker translation studies a reality. This combined with the ability to build highly flexible, multiplexed assays will ensure that the technology will have an impact in the detection and monitoring of complex heterogeneous diseases.

\section{Acknowledgement}

Nick Tomczyk, Mark Roberts, Dan Kenny and David Little are kindly acknowledged for making the quantitative sulfadimethoxine LC-MS data and results available. Jason Wildgoose is acknowledged for technical discussions, comments and advice. This work was partly supported by the John and Lucille van Geest Foundation and the National Institute for Health Research Leicester Cardiovascular Biomedical Research Unit.

\section{Captions}

Figure 1. Full scan tandem quadrupole MS/MS (A), oa-ToF MS/MS (B) and EDC oa-ToF MS/MS (C) spectra of FPEVDVLTK $-{ }^{13} \mathrm{C}_{6}{ }^{15} \mathrm{~N}_{2}$. The precursor and EDC oa-ToF $\mathrm{m} / \mathrm{z}$ values were 528.3 and 682.4 , respectively. The $B$ and $C$ panels are scaled to absolute $\mathrm{m} / \mathrm{z}$ 682.4 product ion intensity values with only the product ion masses in the range of interest transmitted with EDC oa-ToF MS/MS.

Figure 2. Raw summed tandem quadrupole MRM transition abundances as a function of replicate experiments $(n=50)$ for SIL peptides FPEVDVLTK $-{ }^{13} C_{6}{ }^{15} N_{2}$, TAAQNLYEK${ }^{13} \mathrm{C}_{6}{ }^{15} \mathrm{~N}_{2}$, and TGLQEVEVK $-{ }^{13} \mathrm{C}_{6}{ }^{15} \mathrm{~N}_{2}$ spiked at a fixed level in different, independent undepleted plasma digest samples (A), raw summed transition intensity variability (B), intra peptide normalized transition intensity variability $(C)$, and peptide retention time variability (D).

Figure 3. Mobility enabled oa-ToF MRM methods. (A) Precursor ion mobility separation followed by transfer CID including EDC for selected target masses and (B) trap CID followed by product ion mobility separation.

Figure 4. Standard oa-ToF MRM with EDC (A) and trap CID followed by product ion mobility separation (B) for 62.5 amol of SIL labeled GYSIFSYATK $-{ }^{13} \mathrm{C}_{6}{ }^{15} \mathrm{~N}_{2}$ injected oncolumn, monitoring fragments y5 ( $m / z 577.3)$, y6 $(m / z ~ 724.4)$, y7 $(m / z ~ 837.5)$, and y8 $(m / z$ (EDC) 924.5). See section Experimental Conditions and Supplementary Table 1 for additional experimental and MRM details.

Figure 5. (A) Precursor isotope IM separation of two peptides with $A_{0} m / z 856.8$ (spheres) and $A_{0} \mathrm{~m} / z 857.0$ (squares) co-eluting and co-isolated at 78.6 and $78.5 \mathrm{~min}$, respectively, followed by (B) IM separation of an associated product ion to both precursors with $m / z$ 527.3. A third product ion with $m / z$ 528.3, originating from precursor $m / z 856.8$ was detected (not annotated) that partially $m / z$ overlapped with the isotopes of the 527.3 product ion but was separated in the IM domain. See section Experimental Conditions for additional experimental and MRM details. 
Figures 6. Multivariate OPLS-DA analysis showing the separation and classification of patient and control samples. Circle $=$ normal healthy patients; triangles $=$ heart failure patients (HFPEF or HFREF). The model indicates that disease can be classified using a multiplexed tandem quadrupole LC-MRM-MS based assay.

Figure 7. Univariate analysis of ApoA1 (A), CRP (B) and SERPING1 (C) in HFPEF and HFREF and receiver operating curve performance analysis of peptide surrogates for Apo1, CRP and SERPING1 (D), respectively.

\section{References}

1. Current two-dimensional electrophoresis technology for proteomics. Görg A, Weiss W, Dunn MJ. Proteomics. 2004 Dec;4(12):3665-85.

2. High-resolution two-dimensional electrophoresis. Weiss W, Görg A. Methods Mol Biol. 2009;564:13-32.

3. Identifying proteins from two-dimensional gels by molecular mass searching of peptide fragments in protein sequence databases. Henzel WJ, Billeci TM, Stults JT, Wong SC, Grimley C, Watanabe C. Proc Natl Acad Sci U S A. 1993 Jun $1 ; 90(11): 5011-5$.

4. Femtomole sequencing of proteins from polyacrylamide gels by nano-electrospray mass spectrometry. Wilm M, Shevchenko A, Houthaeve T, Breit S, Schweigerer L, Fotsis T, Mann M. Nature. 1996 Feb 1;379(6564):466-9.

5. Valentine SJ, Plasencia MD, Liu XY, Krishnan M, Naylor S, Udseth HR, Smith RD, Clemmer DE. Toward plasma proteome profiling with ion mobility-mass spectrometry. Journal of Proteome Research 2006; 5: 2977.

6. An Investigation of the Mobility Separation of Some Peptide and Protein Ions Using a New Hybrid Quadrupole/Travelling Wave IMS/OA-ToF Instrument. Pringle SD, Giles K, Wildgoose JL, Williams JP, Slade SE, Thalassinos K, Bateman RH, Bowers MT, Scrivens, J. Int J Mass Spectrom. 2007, 261, 1-12.

7. Accurate quantitation of protein expression and site-specific phosphorylation. Oda Y, Huang K, Cross FR, Cowburn D, Chait BT. Proc Natl Acad Sci U S A. 1999 Jun 8;96(12):6591-6.

8. Proteolytic 180 labeling for comparative proteomics: model studies with two serotypes of adenovirus. Yao X, Freas A, Ramirez J, Demirev PA, Fenselau C. Anal Chem. 2001 Jul 1;73(13):2836-42.

9. Quantitative analysis of complex protein mixtures using isotope-coded affinity tags. Gygi SP, Rist B, Gerber SA, Turecek F, Gelb MH, Aebersold R. Nat Biotechnol. 1999 Oct;17(10):994-9.

10. Stable isotope labeling by amino acids in cell culture, SILAC, as a simple and accurate approach to expression proteomics. Ong SE, Blagoev B, Kratchmarova I, Kristensen DB, Steen H, Pandey A, Mann M. Mol Cell Proteomics. 2002 May;1(5):376-86.

11. Multiplex peptide stable isotope dimethyl labeling for quantitative proteomics. Boersema PJ, Raijmakers R, Lemeer S, Mohammed S, Heck AJ. Nat Protoc. 2009;4(4):484-94.

12. Multiplexed protein quantitation in Saccharomyces cerevisiae using amine-reactive isobaric tagging reagents. Ross PL, Huang YN, Marchese JN, Williamson B, Parker K, Hattan S, Khainovski N, Pillai S, Dey S, Daniels S, Purkayastha S, Juhasz P, 
Martin S, Bartlet-Jones M, He F, Jacobson A, Pappin DJ. Mol Cell Proteomics. 2004 Dec;3(12):1154-69.

13. Tandem mass tags: a novel quantification strategy for comparative analysis of complex protein mixtures by MS/MS. Thompson A, Schäfer J, Kuhn K, Kienle S, Schwarz J, Schmidt G, Neumann T, Johnstone R, Mohammed AK, Hamon C. Anal Chem. 2003 Apr 15;75(8):1895-904.

14. Quantification of proteins and metabolites by mass spectrometry without isotopic labeling or spiked standards. Wang W, Zhou H, Lin H, Roy S, Shaler TA, Hill LR, Norton S, Kumar P, Anderle M, Becker CH. Anal Chem. 2003 Sep 15;75(18):481826.

15. Quantitative proteomic analysis by accurate mass retention time pairs. Silva JC, Denny R, Dorschel CA, Gorenstein M, Kass IJ, Li GZ, McKenna T, Nold MJ, Richardson K, Young P, Geromanos S. Anal Chem. 2005 Apr 1;77(7):2187-200.

16. Informatics platform for global proteomic profiling and biomarker discovery using liquid chromatography-tandem mass spectrometry. Radulovic D, Jelveh S, Ryu S, Hamilton TG, Foss E, Mao Y, Emili A. Mol Cell Proteomics. 2004 Oct;3(10):984-97

17. Absolute quantification of proteins by LCMSE: a virtue of parallel MS acquisition. Silva JC, Gorenstein MV, Li GZ, Vissers JP, Geromanos SJ. Mol Cell Proteomics. 2006 Jan; 5(1):144-56.

18. Using annotated peptide mass spectrum libraries for protein identification. Craig $R$, Cortens JC, Fenyo D, Beavis RC. J Proteome Res. 2006 Aug;5(8):1843-9.

19. PRIDE: the proteomics identifications database. Martens $L$, Hermjakob $H$, Jones $P$, Adamski M, Taylor C, States D, Gevaert K, Vandekerckhove J, Apweiler R. Proteomics. 2005 Aug;5(13):3537-45.

20. Quantitative mass spectrometric multiple reaction monitoring assays for major plasma proteins. Anderson L, Hunter CL. Mol Cell Proteomics. 2006 Apr;5(4):57388.

21. Quantitative, multiplexed assays for low abundance proteins in plasma by targeted mass spectrometry and stable isotope dilution. Keshishian $\mathrm{H}$, Addona $\mathrm{T}$, Burgess $\mathrm{M}$, Kuhn E, Carr SA. Mol Cell Proteomics. 2007 Dec;6(12):2212-29.

22. Selected reaction monitoring for quantitative proteomics: a tutorial. Lange $V$, Picotti P, Domon B, Aebersold R. Mol Syst Biol. 2008;4:222.

23. Parallel reaction monitoring for high resolution and high mass accuracy quantitative, targeted proteomics. Peterson AC, Russell JD, Bailey DJ, Westphall MS, Coon JJ. Mol Cell Proteomics. 2012 Nov;11(11):1475-88

24. Bhandari SS, Narayan H, Jones DJL, Struck J, Bergman A, Squire IB, Ng LL (2015) Plasma growth hormone levels in patients with acute heart failure with reduced and preserved ejection fraction. Eur J Heart Fail. Accepted for publication.

25. Qualitative and quantitative characterization of plasma proteins when incorporating traveling wave ion mobility into a liquid chromatography-mass spectrometry workflow for biomarker discovery: use of product ion quantitation as an alternative data analysis tool for label free quantitation. Daly CE, Ng LL, Hakimi A, Willingale R, Jones DJ. Anal Chem. 2014 Feb 18;86(4):1972-9.

26. Practical applications of integrated microfluidics for peptide quantification. Chambers EE, Lame ME, Rainville PD, Murphy J, Johnson J, Fountain KJ, Plumb RS, Claise P, Smith NW. Bioanalysis. 2015;7(7):857-67.

27. Enhancements in travelling wave ion mobility resolution. Giles K, Williams JP, Campuzano I. Rapid Commun Mass Spectrom. 2011 Jun 15;25(11):1559-66 
28. MRM-based multiplexed quantitation of 67 putative cardiovascular disease biomarkers in human plasma. Domanski D, Percy AJ, Yang J, Chambers AG, Hill JS, Freue GV, Borchers CH. Proteomics. 2012 Apr;12(8):1222-43.

29. Candidate-based proteomics in the search for biomarkers of cardiovascular disease. Anderson L.J Physiol. 2005 Feb 15;563(Pt 1):23-60.

30. Skyline: an open source document editor for creating and analyzing targeted proteomics experiments. MacLean B, Tomazela DM, Shulman N, Chambers $M$, Finney GL, Frewen B, Kern R, Tabb DL, Liebler DC, MacCoss MJ. Bioinformatics. 2010 Apr 1;26(7):966-8.

31. Why have so few proteomic biomarkers "survived" validation? (Sample size and independent validation considerations). Hernández B, Parnell A, Pennington SR. Proteomics. 2014 Jul;14(13-14):1587-92.

32. Multi-site assessment of the precision and reproducibility of multiple reaction monitoring-based measurements of proteins in plasma. Addona TA, Abbatiello SE, Schilling B, Skates SJ, Mani DR, Bunk DM, Spiegelman $\mathrm{CH}$, Zimmerman LJ, Ham AJ, Keshishian $\mathrm{H}$, Hall SC, Allen S, Blackman RK, Borchers $\mathrm{CH}$, Buck $\mathrm{C}$, Cardasis HL, Cusack MP, Dodder NG, Gibson BW, Held JM, Hiltke T, Jackson A, Johansen EB, Kinsinger CR, Li J, Mesri M, Neubert TA, Niles RK, Pulsipher TC, Ransohoff D, Rodriguez $H$, Rudnick PA, Smith $D$, Tabb DL, Tegeler TJ, Variyath AM, VegaMontoto LJ, Wahlander A, Waldemarson S, Wang M, Whiteaker JR, Zhao L, Anderson NL, Fisher SJ, Liebler DC, Paulovich AG, Regnier FE, Tempst P, Carr SA. Nat Biotechnol. 2009 Jul;27(7):633-41.

33. Interlaboratory study characterizing a yeast performance standard for benchmarking LC-MS platform performance. Paulovich AG, Billheimer D, Ham AJ, Vega-Montoto L, Rudnick PA, Tabb DL, Wang P, Blackman RK, Bunk DM, Cardasis $H L$, Clauser $K R$, Kinsinger $C R$, Schilling $B$, Tegeler TJ, Variyath $A M$, Wang $M$, Whiteaker JR, Zimmerman LJ, Fenyo D, Carr SA, Fisher SJ, Gibson BW, Mesri M, Neubert TA, Regnier FE, Rodriguez $\mathrm{H}$, Spiegelman C, Stein SE, Tempst P, Liebler DC. Mol Cell Proteomics. 2010 Feb;9(2):242-54.

34. Demonstrating the feasibility of large-scale development of standardized assays to quantify human proteins. Kennedy JJ, Abbatiello SE, Kim K, Yan P, Whiteaker JR, Lin $C$, Kim JS, Zhang $Y$, Wang $X$, Ivey RG, Zhao L, Min H, Lee $Y$, Yu MH, Yang EG, Lee C, Wang P, Rodriguez H, Kim Y, Carr SA, Paulovich AG. Nat Methods. 2014 Feb;11(2):149-55.

35. Large-scale inter-laboratory study to develop, analytically validate and apply highly multiplexed, quantitative peptide assays to measure cancer-relevant proteins in plasma. Abbatiello SE, Schilling B, Mani DR, Zimmerman LJ, Hall SC, MacLean B, Albertolle M, Allen S, Burgess M, Cusack MP, Ghosh M, Hedrick V, Held JM, Inerowicz $H D$, Jackson $A$, Keshishian $H$, Kinsinger $C R$, Lyssand J, Makowski L, Mesri M, Rodriguez H, Rudnick P, Sadowski P, Sedransk N, Shaddox K, Skates SJ, Kuhn E, Smith D, Whiteaker JR, Whitwell C, Zhang S, Borchers CH, Fisher SJ, Gibson BW, Liebler DC, MacCoss MJ, Neubert TA, Paulovich AG, Regnier FE, Tempst P, Carr SA. Mol Cell Proteomics. 2015 Feb 18. pii: mcp.M114.047050.

36. Quantitation of 47 human tear proteins using high resolution multiple reaction monitoring (HR-MRM) based-mass spectrometry. Tong L, Zhou XY, Jylha A, Aapola U, Liu DN, Koh SK, Tian D, Quah J, Uusitalo H, Beuerman RW, Zhou L. J Proteomics. 2015 Feb 6;115:36-48.

37. Identification and validation of novel candidate protein biomarkers for the detection of human gastric cancer. Humphries JM, Penno MA, Weiland F, Klingler-Hoffmann 
M, Zuber A, Boussioutas A, Ernst M, Hoffmann P. Biochim Biophys Acta. 2014 May;1844(5):1051-8.

38. Multiplexed, Scheduled, High-Resolution Parallel Reaction Monitoring on a Full Scan QqTOF Instrument with Integrated Data-Dependent and Targeted Mass Spectrometric Workflows. Schilling B, MacLean B, Held JM, Sahu AK, Rardin MJ, Sorensen DJ, Peters T, Wolfe AJ, Hunter CL, MacCoss MJ, Gibson BW. Anal Chem. 2015 Oct 20;87(20):10222-9.

39. Selectivity of LC-MS/MS analysis: implication for proteomics experiments. Gallien S, Duriez E, Demeure K, Domon B. J Proteomics. 2013 Apr 9;81:148-58.

40. Simplified and efficient quantification of low-abundance proteins at very high multiplex via targeted mass spectrometry. Burgess MW, Keshishian $H$, Mani DR, Gillette MA, Carr SA. Mol Cell Proteomics. 2014 Apr;13(4):1137-49.

41. Influence of the 6th and 10th spatial harmonics on the peak shape of a quadrupole mass filter with round rods. Douglas DJ, Konenkov NV. Rapid Commun Mass Spectrom. 2002;16(15):1425-31.

42. Ion dispersion near parallel wire grids in orthogonal acceleration time-of-flight mass spectrometry: predicting the effect of the approach angle on resolution. Lewin M1, Guilhaus M, Wildgoose J, Hoyes J, Bateman B. Rapid Commun Mass Spectrom. 2002;16(6):609-15.

43. Ion mobility tandem mass spectrometry enhances performance of bottom-up proteomics. Helm D, Vissers JP, Hughes CJ, Hahne H, Ruprecht B, Pachl F, Grzyb A, Richardson K, Wildgoose J, Maier SK, Marx H, Wilhelm M, Becher I, Lemeer S, Bantscheff M, Langridge JI, Kuster B. Mol Cell Proteomics. 2014 Aug 8. pii: mcp.M114.041038.

44. Search for novel circulating cancer chemopreventive biomarkers of dietary rice bran intervention in $\mathrm{Apc}(\mathrm{Min})$ mice model of colorectal carcinogenesis, using proteomic and metabolic profiling strategies. Norris L, Malkar A, Horner-Glister E, Hakimi A, Ng LL, Gescher AJ, Creaser C, Sale S, Jones DJ. Mol Nutr Food Res. 2015 Sep;59(9):1827-36.

45. A novel precursor ion discovery method on a hybrid quadrupole orthogonal acceleration time-of-flight (Q-TOF) mass spectrometer for studying protein phosphorylation. Bateman RH, Carruthers R, Hoyes JB, Jones C, Langridge JI, Millar A, Vissers JP. J Am Soc Mass Spectrom. 2002 Jul;13(7):792-803.

46. The detection, correlation, and comparison of peptide precursor and product ions from data independent LC-MS with data dependant LC-MS/MS. Geromanos SJ, Vissers JP, Silva JC, Dorschel CA, Li GZ, Gorenstein MV, Bateman RH, Langridge JI. Proteomics. 2009 Mar;9(6):1683-95.

47. Current databases on biological variation: pros, cons and progress. Ricós $C$, Alvarez V, Cava F, García-Lario JV, Hernández A, Jiménez CV, Minchinela J, Perich C, Simón M. Scand J Clin Lab Invest. 1999 Nov;59(7):491-500.

48. https://www.westgard.com/biodatabase1.htm

49. The fundamental flaws of immunoassays and potential solutions using tandem mass spectrometry. Hoofnagle AN, Wener MH. J Immunol Methods. 2009 Aug $15 ; 347(1-2): 3-11$.

50. Sources of technical variability in quantitative LC-MS proteomics: human brain tissue sample analysis. Piehowski PD, Petyuk VA, Orton DJ, Xie F, Moore RJ, Ramirez-Restrepo M, Engel A, Lieberman AP, Albin RL, Camp DG, Smith RD, Myers AJ. J Proteome Res. 2013 May 3;12(5):2128-37. 
51. High efficiency and quantitatively reproducible protein digestion by trypsinimmobilized magnetic microspheres. Sun L, Li Y, Yang P, Zhu G, Dovichi NJ. J Chromatogr A. 2012 Jan 13;1220:68-74.

52. Reproducibility of tryptic digestion investigated by quantitative fourier transform ion cyclotron resonance mass spectrometry. Hagman C, Ramström M, Jansson M, James P, Håkansson P, Bergquist J. J Proteome Res. 2005 Mar-Apr;4(2):394-9.

53. Comprehensive analysis of protein digestion using six trypsins reveals the origin of trypsin as a significant source of variability in proteomics. Walmsley SJ, Rudnick PA, Liang Y, Dong Q, Stein SE, Nesvizhskii AI. J Proteome Res. 2013 Dec 6;12(12):5666-80.

54. mProphet: automated data processing and statistical validation for large-scale SRM experiments. Reiter L, Rinner O, Picotti $P$, Hüttenhain $R$, Beck $M$, Brusniak MY, Hengartner MO, Aebersold R. Nat Methods. 2011 May;8(5):430-5.

55. Automated detection of inaccurate and imprecise transitions in peptide quantification by multiple reaction monitoring mass spectrometry. Abbatiello SE, Mani DR, Keshishian H, Carr SA. Clin Chem. 2010 Feb;56(2):291-305.

56. Applications of a travelling wave-based radio-frequency-only stacked ring ion guide. Giles K, Pringle SD, Worthington KR, Little D, Wildgoose JL, Bateman RH. Rapid Commun Mass Spectrom. 2004;18(20):2401-14.

57. Investigation of the advanced functionalities of a hybrid quadrupole orthogonal acceleration time-of-flight mass spectrometer. Weaver PJ, Laures AM, Wolff JC. Rapid Commun Mass Spectrom. 2007;21(15):2415-21.

59. ETD allows for native surface mapping of a $150 \mathrm{kDa}$ noncovalent complex on a commercial Q-TWIMS-TOF instrument. Lermyte F, Konijnenberg A, Williams JP, Brown JM, Valkenborg D, Sobott F. J Am Soc Mass Spectrom. 2014 Mar;25(3):34350 .

59. Characterization of top-down ETD in a travelling-wave ion guide. Lermyte $F$, Verschueren T, Brown JM, Williams JP, Valkenborg D, Sobott F. Methods. 2015 Nov 1;89:22-9.

60. Bhalla V, Georgiopoulou V, Gupta D, et al. Apolipoprotein A-1 levels and heart failure outcomes. Heart Failure Society of America 2012 Scientific Meeting; September 10, 2012; Seattle, WA. Abstract 229.

61. C-reactive protein in heart failure: prognostic value and the effect of valsartan. Anand IS, Latini R, Florea VG, Kuskowski MA, Rector T, Masson S, Signorini S, Mocarelli P, Hester A, Glazer R, Cohn JN. Circulation. 2005 Sep 6;112(10):142834. Epub 2005 Aug 29. 
Table 1. Configuration and MRM method overview.

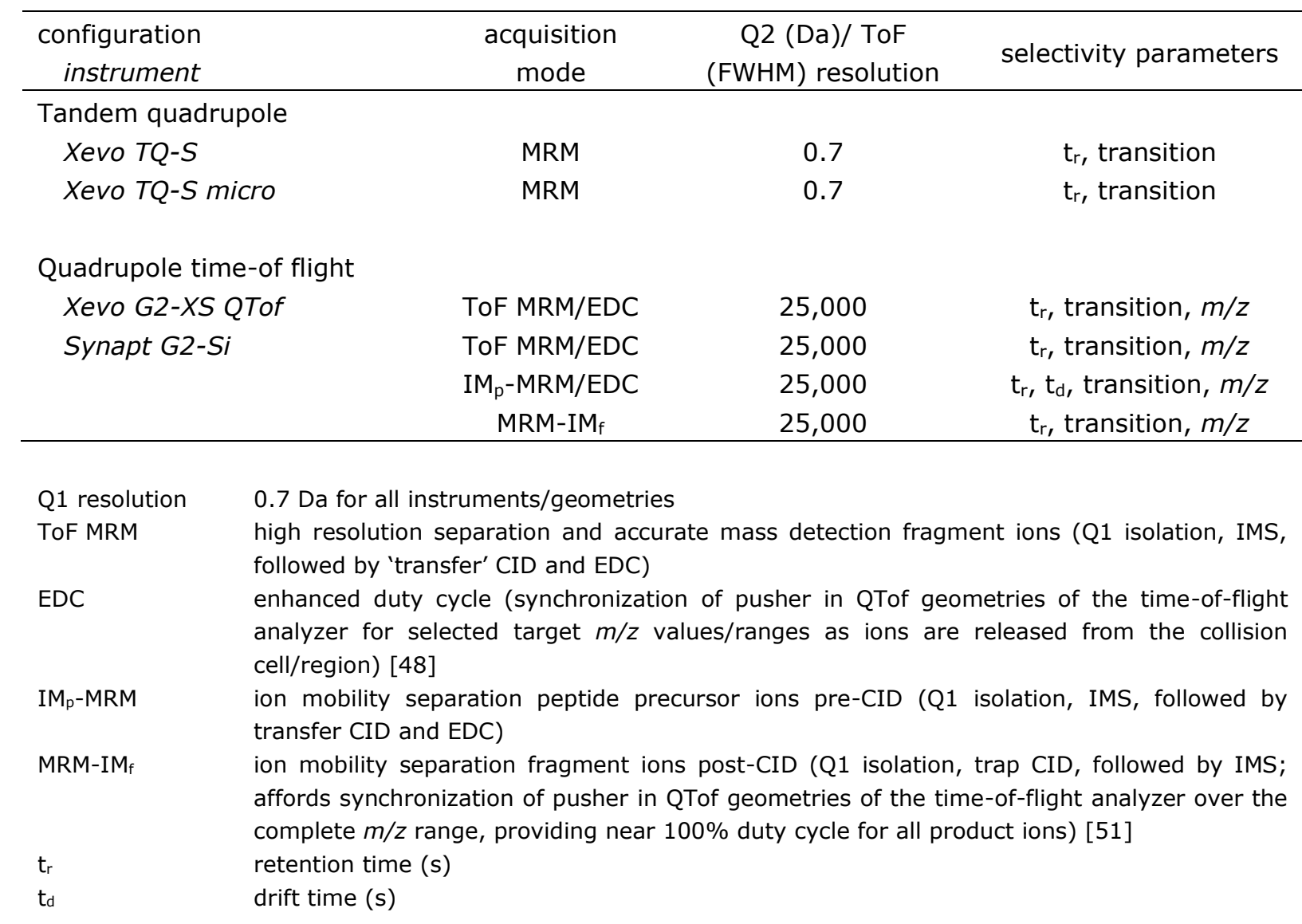


Table 2. Target peptide sequences and proteins, including normal amount and molar concentration plasma levels.

\begin{tabular}{|c|c|c|c|c|}
\hline peptide sequence & entry name & primary gene name & $\begin{array}{l}\text { normal plasma } \\
\text { concentration }(\mathrm{ng} / \mathrm{mL})\end{array}$ & $\begin{array}{l}\text { peptide amount } \\
\text { (nmol/mL plasma) }\end{array}$ \\
\hline LVNEVTEFA[K] & ALBU_HUMAN & ALB & $41,000,000$ & 620 \\
\hline ATEHLSTLSE[K] & APOA1_HUMAN & APOA 1 & $1,400,000$ & 50 \\
\hline TGLQEVEV[K] & CO3_HUMAN & $\mathrm{C} 3$ & $1,300,000$ & 7.0 \\
\hline FPEVDVLT[K] & APOB_HUMAN & APOB & 730,000 & 1.4 \\
\hline FQPTLLTLP[R] & IC1_HUMAN & SERPING1 & 137,000 & 2.6 \\
\hline TAAQNLYE[K] & APOC2_HUMAN & APOC2 & 33,000 & 3.7 \\
\hline LGPLVEQG[R] & APOE_HUMAN & APOE & 40,000 & 1.2 \\
\hline AAAATGTIFTF[R] & IPSP_HUMAN & SERPINA5 & 4,400 & 0.10 \\
\hline EANYIGSD $[\mathrm{K}]$ & SAA1_HUMAN & SAA1 & 4,000 & 0.34 \\
\hline ESDTSYVSL[K] & CRP_HUMAN & CRP & 2,300 & 0.10 \\
\hline \multicolumn{5}{|l|}{ GYSIFSYAT[K] } \\
\hline GFYFNKPTGYGSSS[R] & IGF1_HUMAN & IGF1 & 144 & 0.019 \\
\hline LVNVVLGAHNV[R] & PRTN3_HUMAN & PRTN3 & 23 & 0.000949 \\
\hline ITLYG[R] & NGAL_HUMAN & LCN2 & 87 & 0.00423 \\
\hline SYPGLTSYLV[R] & & & & \\
\hline
\end{tabular}

$[\mathrm{K}]={ }^{13} \mathrm{C}_{6}{ }^{15} \mathrm{~N}_{2}$ labelled; $[\mathrm{R}]={ }^{13} \mathrm{C}_{6}{ }^{15} \mathrm{~N}_{4}$ labelled

ALBU_HUMAN = serum albumin; APOA1_HUMAN = Apolipoprotein A-1; APOB_HUMAN = Apolipoprotein B-100; APOC2_HUMAN = Apolipoprotein C-II; APOE_HUMAN = Apolipoprotein E; CO3_HUMAN = Complement C3; CRP_HUMAN = C-reactive protein; IGF1_HUMAN= Insulin-like growth factor I; PRTN3_HUMAN = Myeloblastin; NGAL_HUMAN = Neutrophil gelatinase-associated; IC1_HUMAN = Plasma protease C1 inhibitor; IPSP_HUMAN = Plasma serine protease inhibitor; SAA1_HUMAN = Serum amyloid A-1 protein 
Table 3. Biological variation [48].

\begin{tabular}{llccc}
\hline entry name & protein name & \multicolumn{2}{c}{ biological variation } & \multirow{2}{*}{ \# references } \\
\cline { 2 - 3 } & & $\mathrm{CV}_{\mathrm{I}}$ & $\mathrm{CV}_{\mathrm{G}}$ & \\
\hline ALBU_HUMAN & Serum albumin & 3.2 & 4.8 & 24 \\
APOA1_HUMAN & Apolipoprotein A-1 & 6.5 & 13.4 & 11 \\
APOB_HUMAN & Apolipoprotein B-100 & 6.9 & 22.8 & 9 \\
CRP_HUMAN & C-reactive protein & 42.2 & 76.3 & 3 \\
CO3_HUMAN & Complement C3 & 5.2 & 15.6 & 2 \\
IGF1_HUMAN & Insulin-like growth factor I & 14.6 & 45.4 & 2 \\
\hline
\end{tabular}

$\mathrm{CV}_{\mathrm{I}}=$ within-subject (intra-individual) coefficient of variation; $\mathrm{CV}_{\mathrm{G}}=$ between-subject (inter-individual) biological variation 
Table 4. Quantitative response, $S / N$ and estimated LLOD of fifteen SIL peptides spiked into undepleted, tryptic digested human serum using tandem quadruple and oa-ToF mass spectrometry in combination with nanoscale LC (see section Experimental for details). The levels tested ranges from 6.25 amol to 1.25 fmol on-column.

\begin{tabular}{|c|c|c|c|c|c|c|c|c|c|c|c|c|}
\hline \multirow[t]{2}{*}{ peptide sequence } & \multicolumn{4}{|c|}{$r^{2}$} & \multicolumn{4}{|c|}{$S / N @ 12.5$ amol on-column } & \multicolumn{4}{|c|}{ estimated LLOD } \\
\hline & MRM1 & MRM2 & oa-ToF1 & oa-ToF2 & MRM1 & MRM2 & oa-ToF1 & oa-ToF2 & MRM1 & MRM2 & oa-ToF1 & oa-ToF2 \\
\hline LVNEVTEFA[K] & 0.9957 & - & 0.9997 & 0.9966 & 3 & - & 5 & 2 & 10 & - & 5 & 15 \\
\hline ATEHLSTLSE[K] & 0.9931 & 0.9955 & 0.9985 & 0.9909 & 2 & 5 & 5 & 8 & 20 & 5 & 5 & 5 \\
\hline TGLQEVEV[K] & 0.9956 & 0.9999 & 0.9992 & 0.9976 & 8 & 10 & 10 & 10 & 10 & 2 & 3 & 5 \\
\hline FPEVDVLT[K] & 0.9959 & 0.9995 & 0.9965 & 0.9998 & 6 & 5 & 6 & 10 & 10 & 10 & 5 & 5 \\
\hline FQPTLLTLP[R] & 0.9995 & 0.9983 & 0.9986 & 0.9989 & 10 & 15 & 10 & 6 & 6 & 3 & 5 & 6 \\
\hline TAAQNLYE[K] & 0.9986 & 0.9994 & 0.9998 & 0.9996 & 5 & 4 & 10 & 8 & 10 & 5 & 3 & 4 \\
\hline LGPLVEQG[R] & 0.9994 & 0.9993 & 0.9992 & 0.9966 & 20 & 30 & 20 & 30 & 2 & 2 & 2 & 1 \\
\hline AAAATGTIFTF[R] & 0.9989 & 0.9994 & 0.9956 & 0.9999 & - & 10 & 8 & 8 & 20 & 10 & 5 & 4 \\
\hline EANYIGSD [K] & 0.9949 & 0.9915 & 0.9982 & 0.9993 & 5 & 8 & 3 & 6 & 5 & 10 & 10 & 5 \\
\hline ESDTSYVSL[K] & 0.9981 & 0.9986 & 0.9995 & 0.9985 & 5 & 5 & 10 & 10 & 5 & 4 & 3 & 4 \\
\hline GYSIFSYAT[K] & 0.9990 & 0.9995 & 0.9989 & 0.9992 & 5 & 10 & 10 & 8 & 5 & 3 & 3 & 5 \\
\hline GFYFNKPTGYGSSS[R] & 0.9984 & 0.9974 & 0.9983 & 0.9973 & - & 20 & 4 & 4 & 15 & 3 & 10 & 10 \\
\hline LVNVVLGAHNV[R] & 0.9952 & 0.9980 & 0.9966 & - & 3 & 4 & - & - & 10 & 10 & 50 & - \\
\hline ITLYG[R] & 0.9987 & 0.9999 & 0.9986 & 0.9955 & 10 & 10 & 12 & 10 & 3 & 3 & 3 & 5 \\
\hline SYPGLTSYLV[R] & 0.9997 & 0.9991 & 0.9976 & 0.9961 & - & - & 2 & 3 & 20 & 30 & 15 & 10 \\
\hline median & & & & & 5 & 10 & 9 & 8 & 10 & 5 & 5 & 5 \\
\hline
\end{tabular}

$r^{2} 1 / x$ weighting; peak-to-peak $S / N ;[K]={ }^{13} \mathrm{C}_{6}{ }^{15} \mathrm{~N}_{4}$ labeled; $[R]={ }^{13} \mathrm{C}_{6}{ }^{15} \mathrm{~N}_{2}$ labeled; - = not calculated (isobaric interfering components or insufficient sensitivity)

MRM1 = Xevo TQ-S micro tandem quadrupole; MRM2 = Xevo TQ-S tandem quadrupole; oa-ToF1 = Xevo G2-XS QTof hybrid oa-ToF; oa-ToF2 =Synapt G2-Si hybrid oa-ToF 
Table 5. Determined plasma concentration of seven target peptides, representing six proteins, with \%CV values using tandem quadruple and oa-ToF mass spectrometry in combination with nanoscale LC (see section Experimental for details).

\begin{tabular}{|c|c|c|c|c|c|c|c|c|}
\hline \multirow[t]{2}{*}{ peptide sequence } & \multicolumn{4}{|c|}{$\begin{array}{l}\text { plasma concentration }(n=11) \\
\text { fmol/140 ng digested plasma }\end{array}$} & \multicolumn{4}{|c|}{$\% \mathrm{CV}$} \\
\hline & MRM1 & MRM2 & oa-ToF1 & oa-ToF2 & MRM1 & MRM2 & oa-ToF1 & oa-ToF2 \\
\hline TGLQEVEVK & 2.86 & 2.73 & 3.2 & 4.5 & 11.1 & 5.4 & 8.4 & 11.5 \\
\hline FPEVDVLTK & 1.11 & 1.18 & 1.2 & 1.3 & 5.4 & 5.1 & 13.1 & 6.4 \\
\hline FQPTLLTLPR & 0.090 & 0.11 & 0.12 & 0.13 & 4.4 & 4.7 & 11.2 & 10.2 \\
\hline TAAQNLYEK & 0.77 & 0.79 & 0.81 & 1.1 & 6.2 & 5.3 & 9.3 & 10.9 \\
\hline LGPLVEQGR & 0.40 & 0.38 & 0.44 & 0.57 & 8.4 & 5.3 & 10.5 & 4.1 \\
\hline ESDTSYVSLK & 0.099 & 0.10 & 0.10 & 0.11 & 12.0 & 5.5 & 10.7 & 5.8 \\
\hline GYSIFSYATK & 0.025 & 0.030 & 0.031 & 0.030 & 18.0 & 10.4 & 13.4 & 7.0 \\
\hline
\end{tabular}

MRM1 = Xevo TQ-S micro tandem quadrupole; MRM2 = Xevo TQ-S tandem quadrupole; oa-ToF1 = Xevo G2-XS QTof hybrid oa-ToF; oa-ToF2 =Synapt G2-Si hybrid oa-ToF 

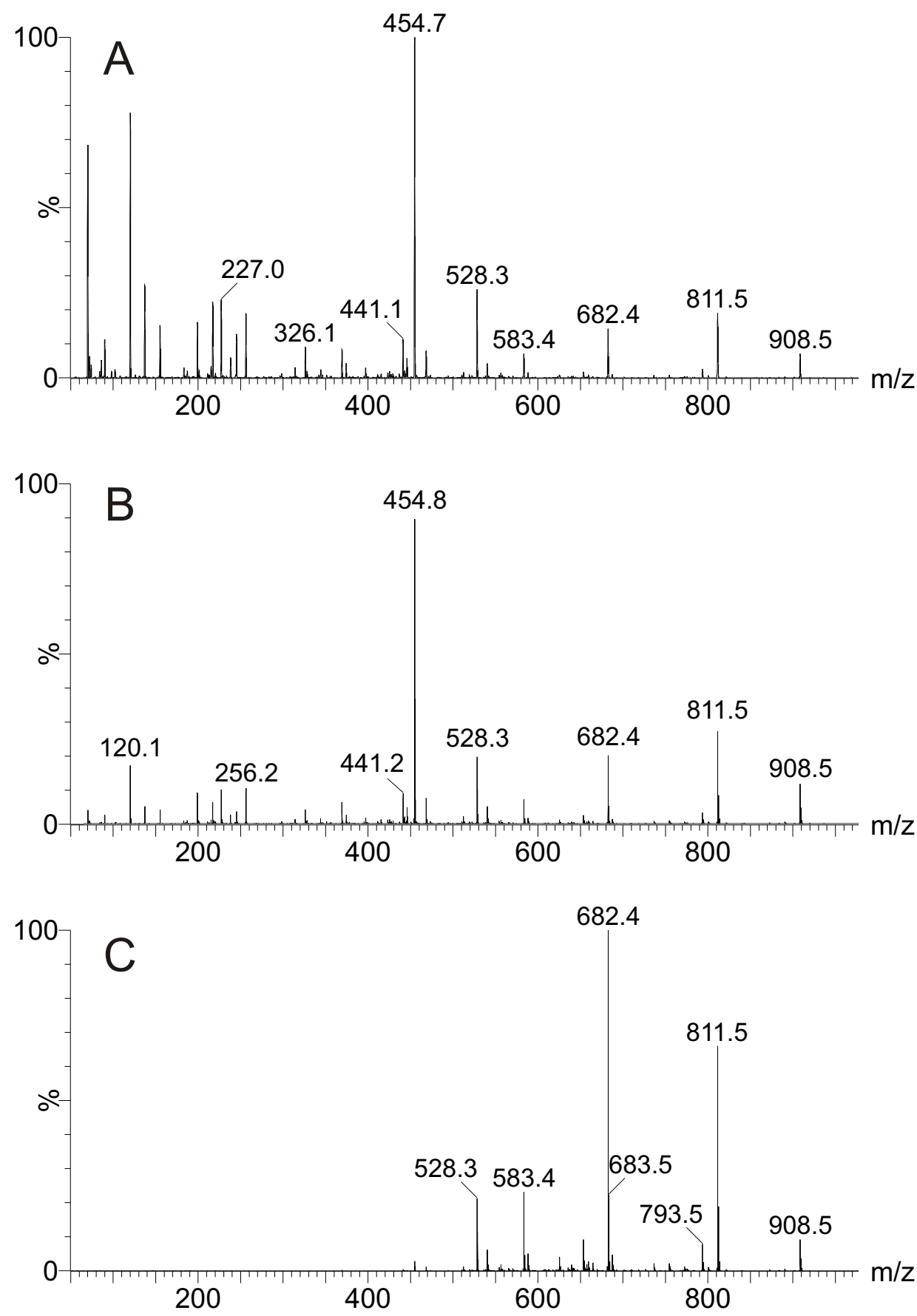

Figure 1. Mbasu et al.

Advances in Quadrupole and Time-of-Flight Mass Spectrometry for Peptide MRM based ... 

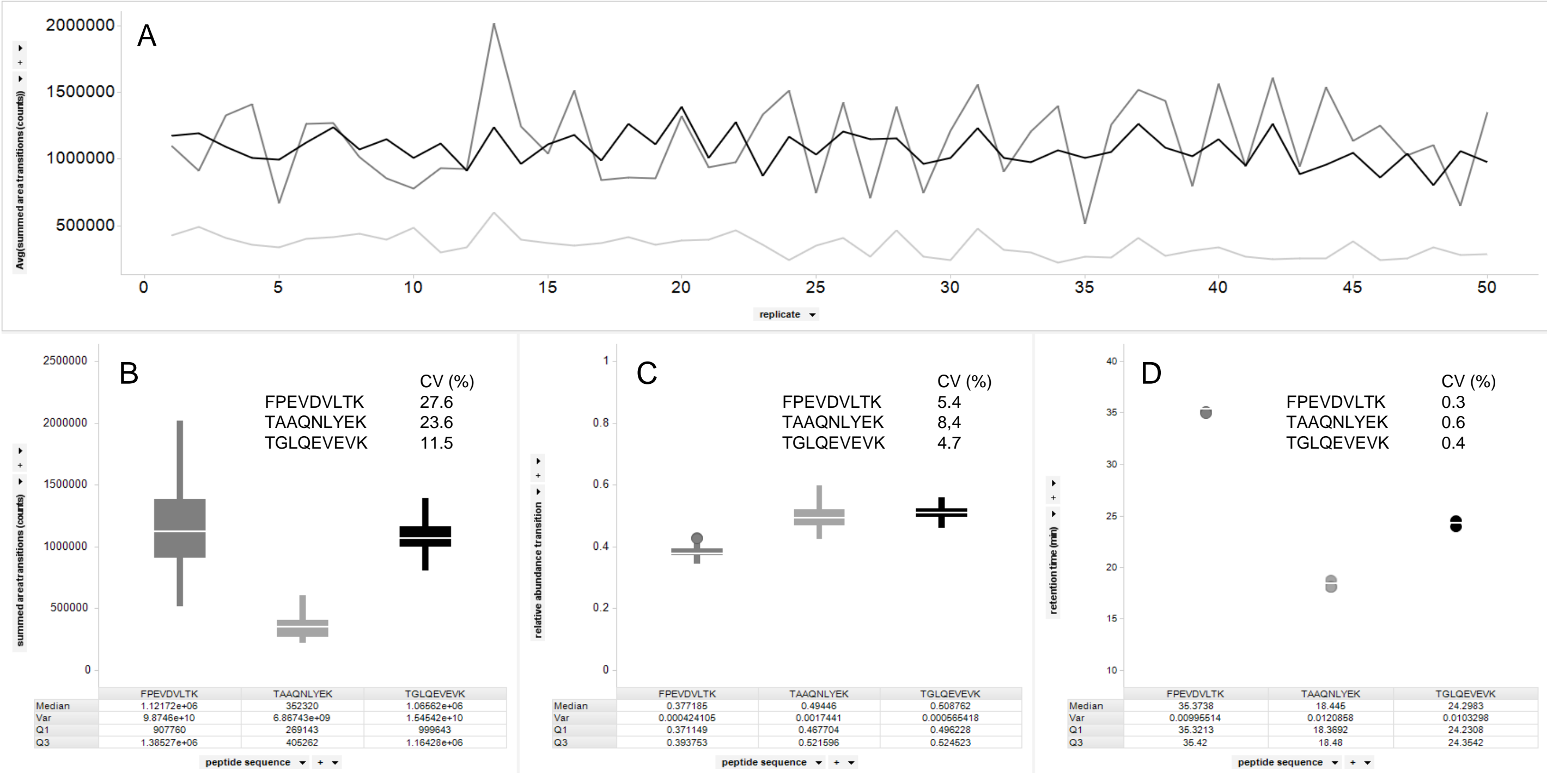

Figure 2. Mbasu et al.

Advances in Quadrupole and Time-of-Flight Mass Spectrometry for Peptide MRM based ... 
quadrupole

trap

ion mobility cell

A एक ०

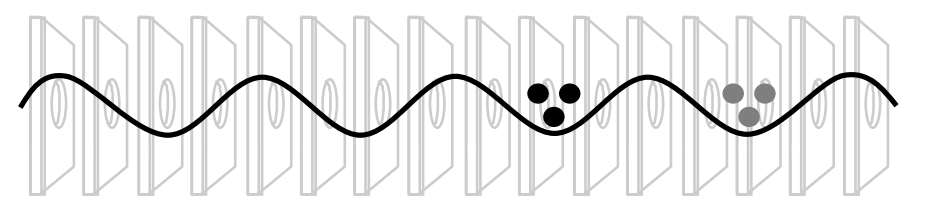

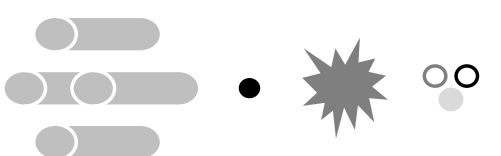

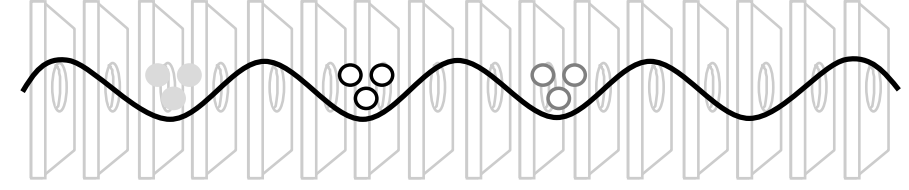

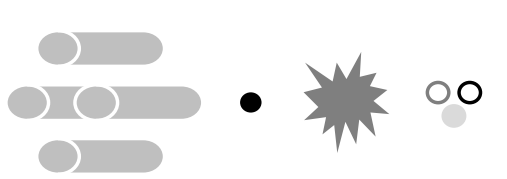

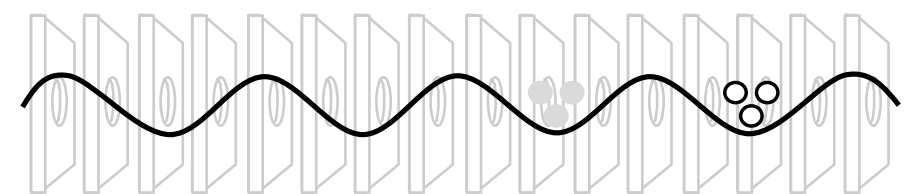

B
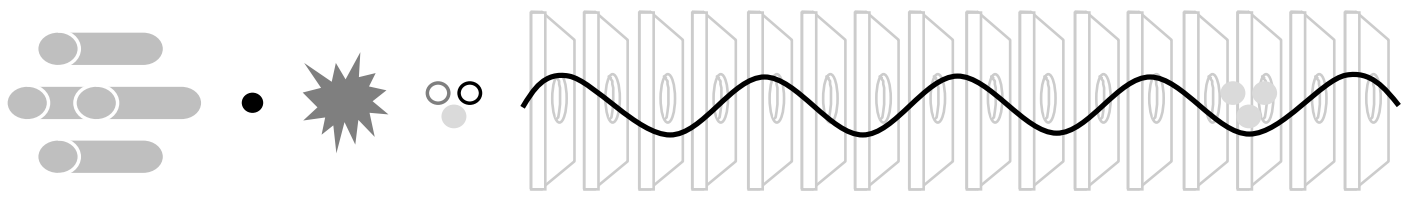

0
0
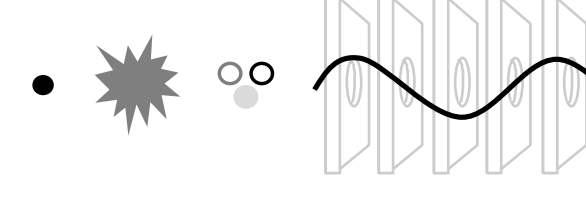

precursor ions transfer

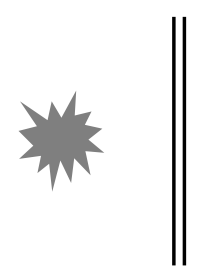

pusher EDC for selected mass

$\infty$

○

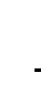

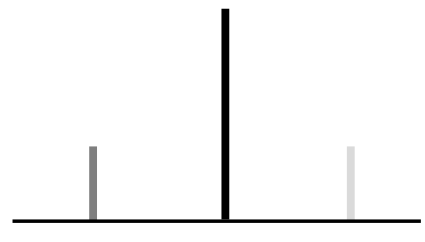

Figure 3. Mbasu et al.
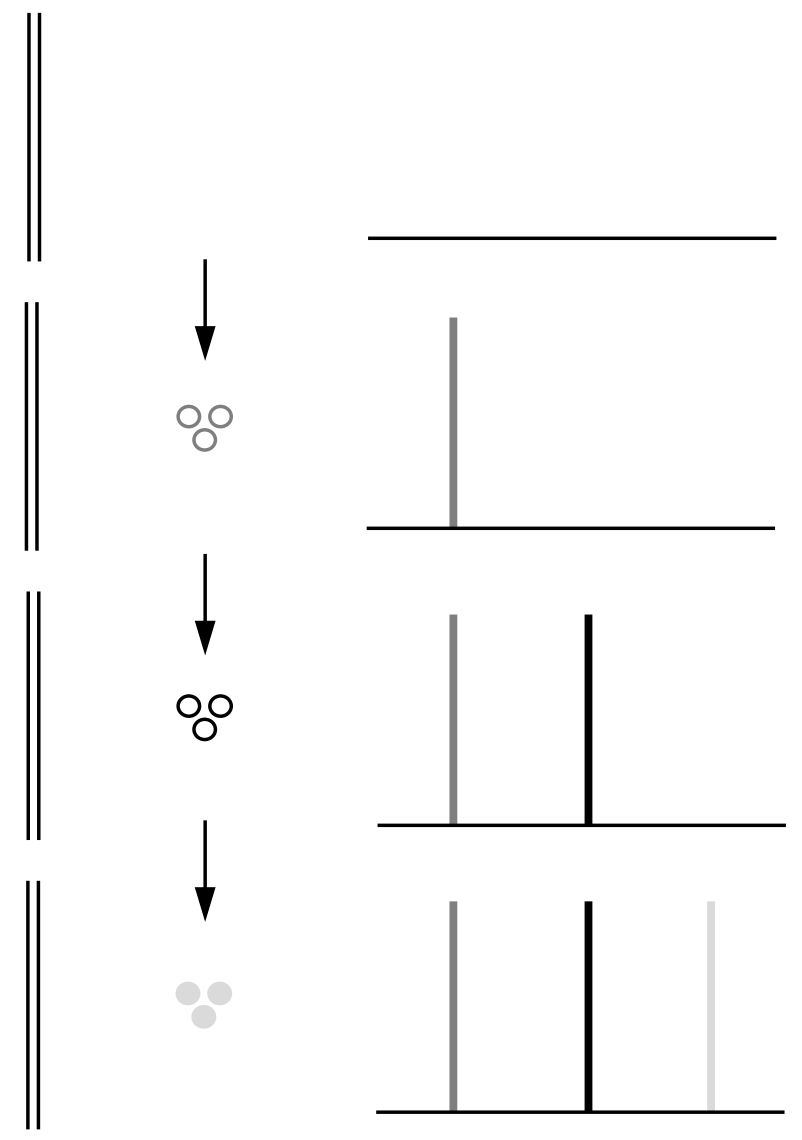

Advances in Quadrupole and Time-of-Flight Mass Spectrometry for Peptide MRM based ... 


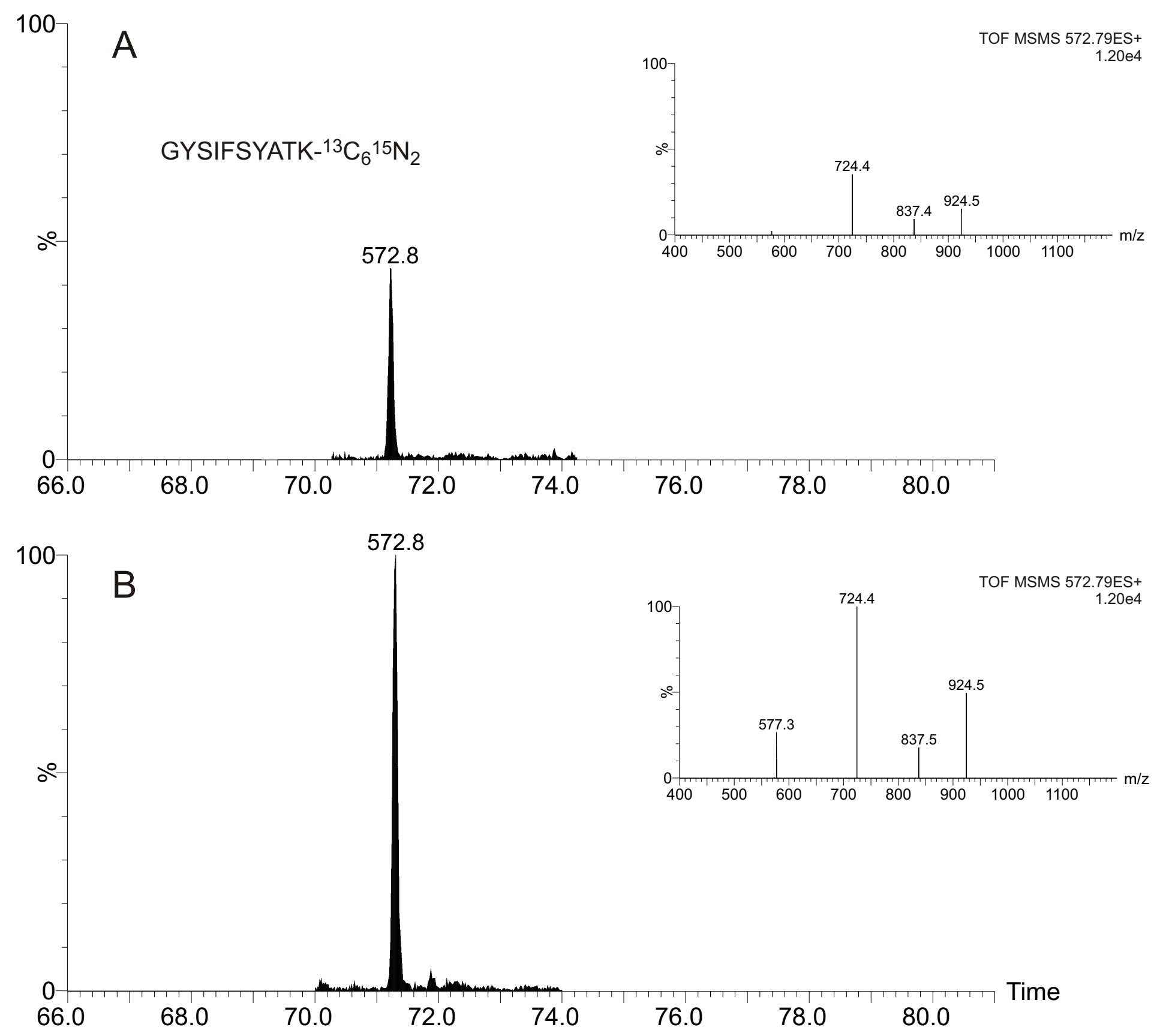

Figure 4. Mbasu et al.

Advances in Quadrupole and Time-of-Flight Mass Spectrometry for Peptide MRM based ... 


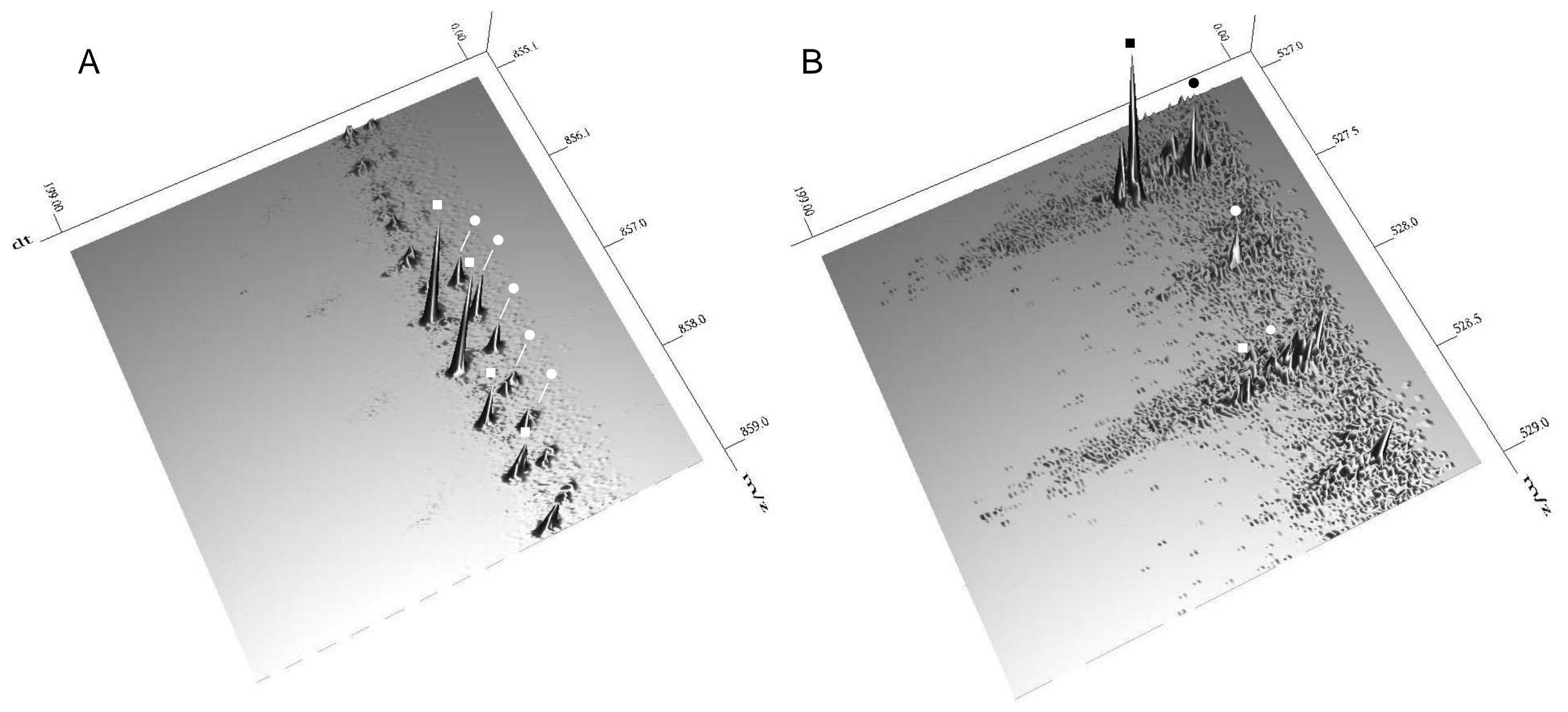

Figure 5. Mbasu et al.

Advances in Quadrupole and Time-of-Flight Mass Spectrometry for Peptide MRM based ... 


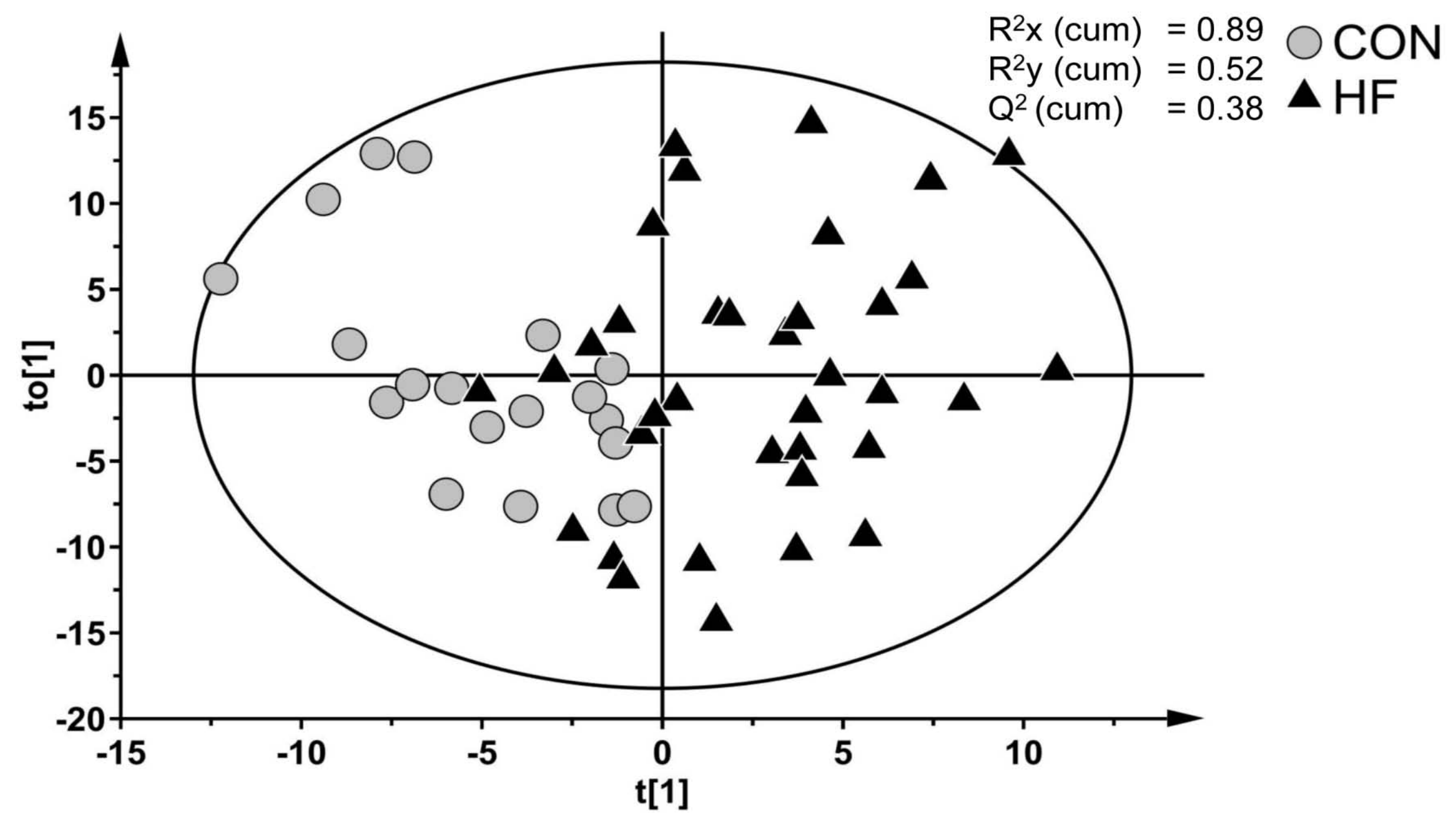

Figure 6. Mbasu et al.

Advances in Quadrupole and Time-of-Flight Mass Spectrometry for Peptide MRM based ... 

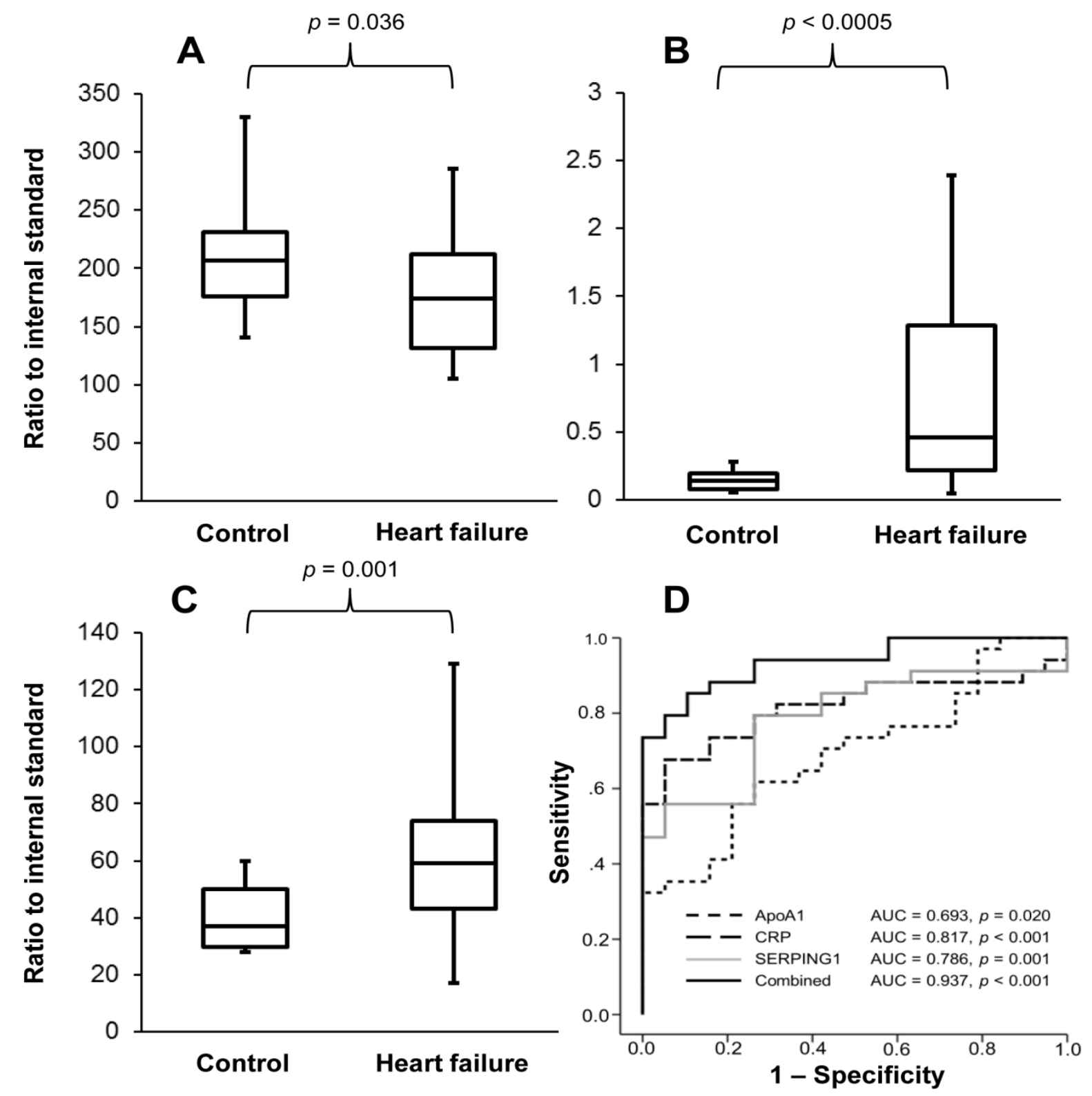

Figure 7. Mbasu et al.

Advances in Quadrupole and Time-of-Flight Mass Spectrometry for Peptide MRM based ... 
Supplementary Table 1. MRM transition overview tandem quadrupole and oa-ToF MRM experiments.

\begin{tabular}{|c|c|c|c|c|c|c|c|}
\hline \multirow[t]{2}{*}{ peptide sequence } & \multirow[t]{2}{*}{$\begin{array}{l}\text { precursor } m / z \\
\text { [charge] }\end{array}$} & \multicolumn{5}{|c|}{$\begin{array}{c}\text { fragment } m / z \\
\text { [fragment ion type] }\end{array}$} & \multirow[t]{2}{*}{$\mathrm{EDC} m / z^{*}$} \\
\hline & & 1 & 2 & 3 & 4 & 5 & \\
\hline LVNEVTEFAK & $575.3[2+]$ & 595.3 [y5] & 694.4 [y6] & 823.4 [y7] & $937.5[\mathrm{y} 8]$ & & 937.5 \\
\hline LVNEVTEFA[K] & $579.3[2+]$ & $603.3[y 5]$ & $702.4[\mathrm{y} 6]$ & $831.4[y 7]$ & $945.5[\mathrm{y} 8]$ & & 945.5 \\
\hline ATEHLSTLSEK & $608.3[2+]$ & $664.4[\mathrm{y} 6]$ & $777.4[\mathrm{y} 7]$ & $914.5[\mathrm{y} 8]$ & & & 777.4 \\
\hline ATEHLSTLSE[K] & $612.3[2+]$ & $672.4[y 6]$ & $785.4[y 7]$ & $922.5[\mathrm{y} 8]$ & & & 785.5 \\
\hline TGLQEVEVK & $501.8[2+]$ & $603.3[\mathrm{y} 5]$ & $731.4[\mathrm{y} 6]$ & $844.5[y 7]$ & 901.5 [y8] & & 731.4 \\
\hline TGLQEVEV[K] & $505.8[2+]$ & 611.3 [y5] & $739.4[\mathrm{y} 6]$ & $852.5[y 7]$ & $909.5[y 8]$ & & 739.4 \\
\hline FPEVDVLTK & $524.3[2+]$ & $575.3[y 5]$ & $674.4[\mathrm{y} 6]$ & $803.5[y 7]$ & $900.5[y 8]$ & & 674.4 \\
\hline FPEVDVLT[K] & $528.3[2+]$ & $583.4[\mathrm{y} 5]$ & $682.4[\mathrm{y} 6]$ & $811.5[y 7]$ & $908.5[\mathrm{y} 8]$ & & 682.4 \\
\hline FQPTLLTLPR & $593.4[2+]$ & $599.4[y 5]$ & $712.5[\mathrm{y} 6]$ & $813.5[y 7]$ & $910.6[\mathrm{y} 8]$ & & 910.6 \\
\hline FQPTLLTLP[R] & $598.4[2+]$ & 609.4 [y5] & $722.5[\mathrm{y} 6]$ & $823.5[y 7]$ & $920.6[y 8]$ & & 920.6 \\
\hline TAAQNLYEK & $519.3[2+]$ & $552.3[\mathrm{y} 4]$ & 666.3 [y5] & $794.4[\mathrm{y} 6]$ & $865.4[y 7]$ & & 865.4 \\
\hline TAAQNLYE[K] & $523.3[2+]$ & $560.3[\mathrm{y} 4]$ & $674.4[\mathrm{y} 5]$ & $802.4[\mathrm{y} 6]$ & $873.5[y 7]$ & & 873.5 \\
\hline LGPLVEQGR & $484.8[2+]$ & $489.2[\mathrm{y} 4]$ & $588.3[\mathrm{y} 5]$ & $701.4[\mathrm{y} 6]$ & $798.4[y 7]$ & $855.5[y 8]$ & 701.4 \\
\hline LGPLVEQG[R] & $489.8[2+]$ & $499.2[\mathrm{y} 4]$ & $598.3[y 5]$ & $711.4[\mathrm{y} 6]$ & $808.5[y 7]$ & $865.5[y 8]$ & 711.4 \\
\hline AAAATGTIFTFR & $613.8[2+]$ & $683.4[\mathrm{y} 5]$ & $784.4[\mathrm{y} 6]$ & $841.5[y 7]$ & $942.5[\mathrm{y} 8]$ & $1013.6[\mathrm{y} 9]$ & 942.5 \\
\hline AAAATGTIFTF[R] & $618.8[2+]$ & $693.4[y 5]$ & $794.4[\mathrm{y} 6]$ & $851.5[y 7]$ & $952.5[\mathrm{y} 8]$ & 1023.6 [y9] & 952.5 \\
\hline EANYIGSDK & $498.7[2+]$ & $519.3[\mathrm{y} 5]$ & $682.3[\mathrm{y} 6]$ & $796.4[y 7]$ & & & 682.3 \\
\hline EANYIGSD $[\mathrm{K}]$ & $502.7[2+]$ & $527.3[y 5]$ & $690.4[y 6]$ & $804.4[y 7]$ & & & 690.4 \\
\hline ESDTSYVSLK & $564.8[2+]$ & $609.4[\mathrm{y} 5]$ & $696.4[\mathrm{y} 6]$ & $797.4[y 7]$ & $912.5[\mathrm{y} 8]$ & & 696.4 \\
\hline ESDTSYVSL[K] & $568.8[2+]$ & $617.4[\mathrm{y} 5]$ & $704.4[\mathrm{y} 6]$ & $805.5[y 7]$ & $920.5[y 8]$ & & 704.4 \\
\hline GYSIFSYATK & $568.8[2+]$ & $569.3[y 5]$ & $716.4[\mathrm{y} 6]$ & $829.4[y 7]$ & $916.5[\mathrm{y} 8]$ & & 916.5 \\
\hline GYSIFSYAT[K] & $572.8[2+]$ & $577.3[y 5]$ & $724.4[\mathrm{y} 6]$ & $837.5[y 7]$ & $924.5[\mathrm{y} 8]$ & & 924.5 \\
\hline GFYFNKPTGYGSSSR & $834.4[2+]$ & $713.3[\mathrm{y} 7]^{\dagger}$ & $814.4[y 8]+$ & 911.4 [y9] & & & 911.4 \\
\hline GFYFNKPTGYGSSS[R] & $839.4[2+]$ & $723.3[y 7]+$ & $824.4[y 8]+$ & 921.4 [y9] & & & 921.4 \\
\hline LVNVVLGAHNVR & $645.9[2+]$ & $653.3[\mathrm{y} 6]$ & $766.4[y 7]$ & $865.5[\mathrm{y} 8]$ & 964.6 [y9] & $1078.6[\mathrm{y} 10]$ & 766.4 \\
\hline LVNVVLGAHNV[R] & $650.9[2+]$ & 663.4 [y6] & $776.4[\mathrm{y} 7]$ & $875.5[y 8]$ & 974.6 [y9] & $1088.6[\mathrm{y} 10]$ & 776.4 \\
\hline ITLYGR & $361.7[2+]$ & $395.2[\mathrm{y} 3]$ & $508.3[\mathrm{y} 4]$ & $609.3[y 5]$ & & & 609.3 \\
\hline ITLYG[R] & $366.7[2+]$ & $405.2[\mathrm{y} 3]$ & $518.3[\mathrm{y} 4]$ & $619.3[\mathrm{y} 5]$ & & & 619.3 \\
\hline SYPGLTSYLVR & $628.3[2+]$ & 637.4 [y5] & 738.4 [y6] & $851.5[y 7]$ & $908.5[y 8]$ & 1005.6 [y9] & 908.5 \\
\hline SYPGLTSYLV[R] & $633.3[2+]$ & 647.4 [y5] & $748.4[\mathrm{y} 6]$ & $861.5[y 7]$ & $918.5[y 8]$ & 1015.6 [y9] & 918.5 \\
\hline
\end{tabular}

$[\mathrm{K}]={ }^{13} \mathrm{C}_{6}{ }^{15} \mathrm{~N}_{4}$ labeled; $[\mathrm{R}]={ }^{13} \mathrm{C}_{6}{ }^{15} \mathrm{~N}_{2}$ labelled; *oa-ToF MRM based acquisitions only; $\dagger<10 \%$ most abundant MRM fragment ion 
Supplementary Table 2. Quantitative response, $S / N$ and estimated LLOD of fifteen SIL peptides spiked into undepleted, tryptic digested human serum using tandem quadruple and oa-ToF mass spectrometry in combination with micro-fluidics (see section Experimental for details). The levels tested ranges from 62.5 amol to $12.5 \mathrm{fmol}$ on-column.

\begin{tabular}{|c|c|c|c|c|c|c|c|c|c|c|c|c|}
\hline \multirow[t]{2}{*}{ peptide sequence } & \multicolumn{4}{|c|}{$r^{2}$} & \multicolumn{4}{|c|}{$S / N @ 125$ amol on-column } & \multicolumn{4}{|c|}{ estimated LLOD } \\
\hline & MRM1 & MRM2 & oa-ToF1 & oa-ToF2 & MRM1 & MRM2 & oa-ToF1 & oa-ToF2 & MRM1 & MRM2 & oa-ToF1 & oa-ToF2 \\
\hline LVNEVTEFA[K] & 0.9982 & - & 0.9983 & 0.9988 & 8 & - & 40 & 20 & 40 & - & 5 & 15 \\
\hline ATEHLSTLSE[K] & 0.9972 & 0.9977 & 0.9930 & 0.9955 & - & 40 & 10 & 10 & 250 & 15 & 20 & 30 \\
\hline TGLQEVEV[K] & 0.9989 & 0.9964 & - & 0.9992 & 5 & 20 & - & 20 & 60 & 15 & - & 15 \\
\hline FPEVDVLT[K] & 0.9994 & 0.9960 & 0.9989 & 0.9969 & 5 & 10 & 10 & 10 & 40 & 20 & 15 & 15 \\
\hline FQPTLLTLP[R] & 0.9992 & 0.9955 & 0.9982 & 0.9970 & 13 & 26 & 100 & 30 & 25 & 20 & 3 & 20 \\
\hline TAAQNLYE[K] & 0.9991 & 0.9989 & 0.9847 & 0.9988 & 2 & 8 & 20 & 20 & 100 & 35 & 10 & 20 \\
\hline LGPLVEQG[R] & 0.9994 & 0.9957 & 0.9992 & 0.9985 & 14 & 37 & 50 & 20 & 20 & 10 & 5 & 20 \\
\hline AAAATGTIFTF[R] & 0.9972 & 0.9987 & 0.9920 & 0.9991 & 30 & 15 & 30 & 8 & 30 & 20 & 20 & 20 \\
\hline EANYIGSD $[\mathrm{K}]$ & 0.9951 & 0.9995 & 0.9991 & 0.9980 & 5 & 10 & 6 & 4 & 50 & 20 & 25 & 50 \\
\hline ESDTSYVSL[K] & 0.9992 & 0.9934 & 0.9987 & 0.9986 & 3 & 16 & 50 & 30 & 50 & 20 & 5 & 20 \\
\hline GYSIFSYAT[K] & 0.9985 & 0.9949 & 0.9997 & 0.9989 & 10 & 17 & 20 & 40 & 30 & 10 & 15 & 10 \\
\hline GFYFNKPTGYGSSS[R] & 0.9993 & 0.9912 & 0.9945 & 0.9957 & - & 15 & 8 & 15 & 250 & 30 & 30 & 40 \\
\hline LVNVVLGAHNV[R] & 0.9946 & 0.9864 & 0.9962 & 0.9928 & 2 & 4 & 3 & - & 125 & 125 & 100 & 150 \\
\hline ITLYG[R] & 0.9996 & 0.9966 & 0.9980 & 0.9992 & 20 & 30 & 30 & 20 & 20 & 10 & 10 & 10 \\
\hline SYPGLTSYLV[R] & 0.9981 & 0.9968 & 0.9995 & 0.9990 & 6 & 20 & 8 & 15 & 50 & 30 & 30 & 20 \\
\hline median & & & & & 6 & 17 & 20 & 20 & 50 & 20 & 15 & 20 \\
\hline
\end{tabular}

$r^{2} 1 / x$ weighting; peak-to-peak $S / N ;[K]={ }^{13} \mathrm{C}_{6}{ }^{15} \mathrm{~N}_{4}$ labeled; $[R]={ }^{13} \mathrm{C}_{6}{ }^{15} \mathrm{~N}_{2}$ labeled; - = not calculated (isobaric interfering components or insufficient sensitivity)

MRM1 = Xevo TQ-S micro tandem quadrupole; MRM2 = Xevo TQ-S tandem quadrupole; oa-ToF1 = Xevo G2-XS OTof hybrid oa-ToF; oa-ToF2 =Synapt G2-Si hybrid oa-ToF 
Supplementary Table 3. Determined plasma concentration of seven target peptides, representing six proteins, with \%CV values using tandem quadruple and oa-ToF mass spectrometry in combination with micro-fluidics (see section Experimental for details).

\begin{tabular}{|c|c|c|c|c|c|c|c|c|}
\hline \multirow[t]{2}{*}{ peptide sequence } & \multicolumn{4}{|c|}{$\begin{array}{l}\text { plasma concentration }(n=7) \\
\text { fmol/140 ng digested plasma }\end{array}$} & \multicolumn{4}{|c|}{$\% \mathrm{CV}$} \\
\hline & MRM1 & MRM2 & oa-ToF1 & oa-ToF2 & MRM1 & MRM2 & oa-ToF1 & oa-ToF2 \\
\hline TGLQEVEVK & 2.78 & 3.7 & 3.1 & 4.4 & 7.7 & 3.9 & 8.5 & 7.5 \\
\hline FPEVDVLTK & 1.14 & 1.16 & 1.25 & 1.19 & 8.9 & 7.6 & 15.0 & 9.9 \\
\hline FQPTLLTLPR & 0.12 & 0.15 & 0.11 & 0.16 & 7.1 & 7.1 & 19.7 & 13.8 \\
\hline TAAQNLYEK & 0.89 & 1.05 & 1.18 & 1.39 & 10.0 & 4.7 & 9.3 & 9.5 \\
\hline LGPLVEQGR & 0.39 & 0.64 & 0.44 & 0.64 & 10.1 & 1.7 & 8.9 & 9.4 \\
\hline ESDTSYVSLK & 0.13 & 0.12 & 0.093 & 0.099 & 18.3 & 10.0 & 15.6 & 10.9 \\
\hline GYSIFSYATK & 0.061 & 0.055 & 0.026 & 0.050 & 10.2 & 9.5 & 23.8 & 11.0 \\
\hline
\end{tabular}

MRM1 = Xevo TQ-S tandem quadrupole micro; MRM2 = Xevo TQ-S tandem quadrupole; oa-ToF1 = Xevo G2-XS QTof hybrid oa-ToF; oa-ToF2 =Synapt G2-Si hybrid oa-ToF 

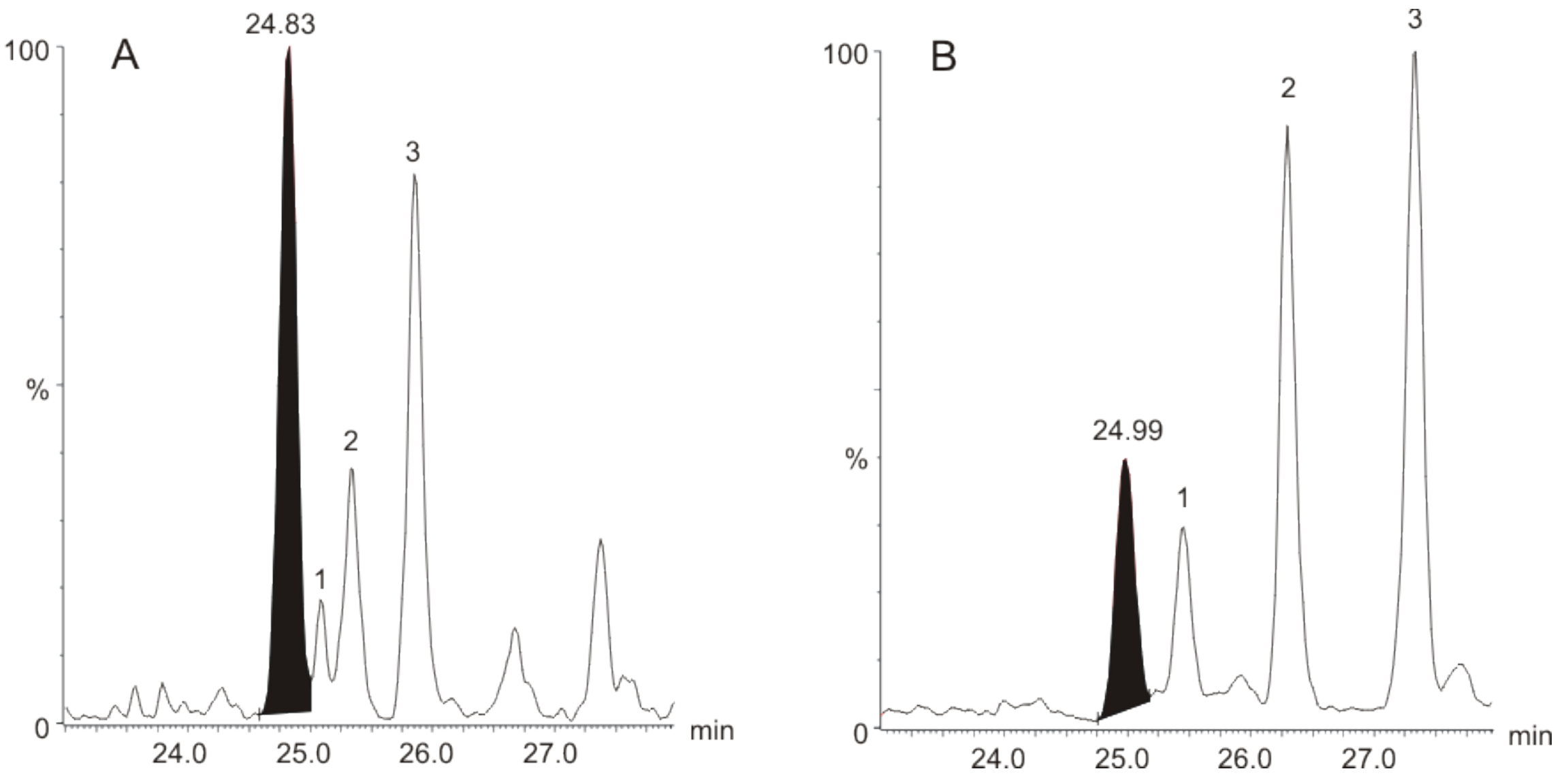

Figure S1. Development of chromatographic conditions for LGPLVEQGR-13 $\mathrm{C}_{6}{ }^{15} \mathrm{~N}_{4}$ (summed MRM transitions $489.784>499.25+489.784>$ $598.318+489.784>711.402+489.784>808.455$ contrasting generic $(A)$ and optimized (B) chromatographic conditions, temperature and gradient slope. The peak of interest is retention time ( $\mathrm{min}$ ) annotated. The ' 1 ', ' 2 ' and ' 3 ' components are isobaric species with one or more shared transitions. See section Experimental Conditions for final chromatographic conditions. 

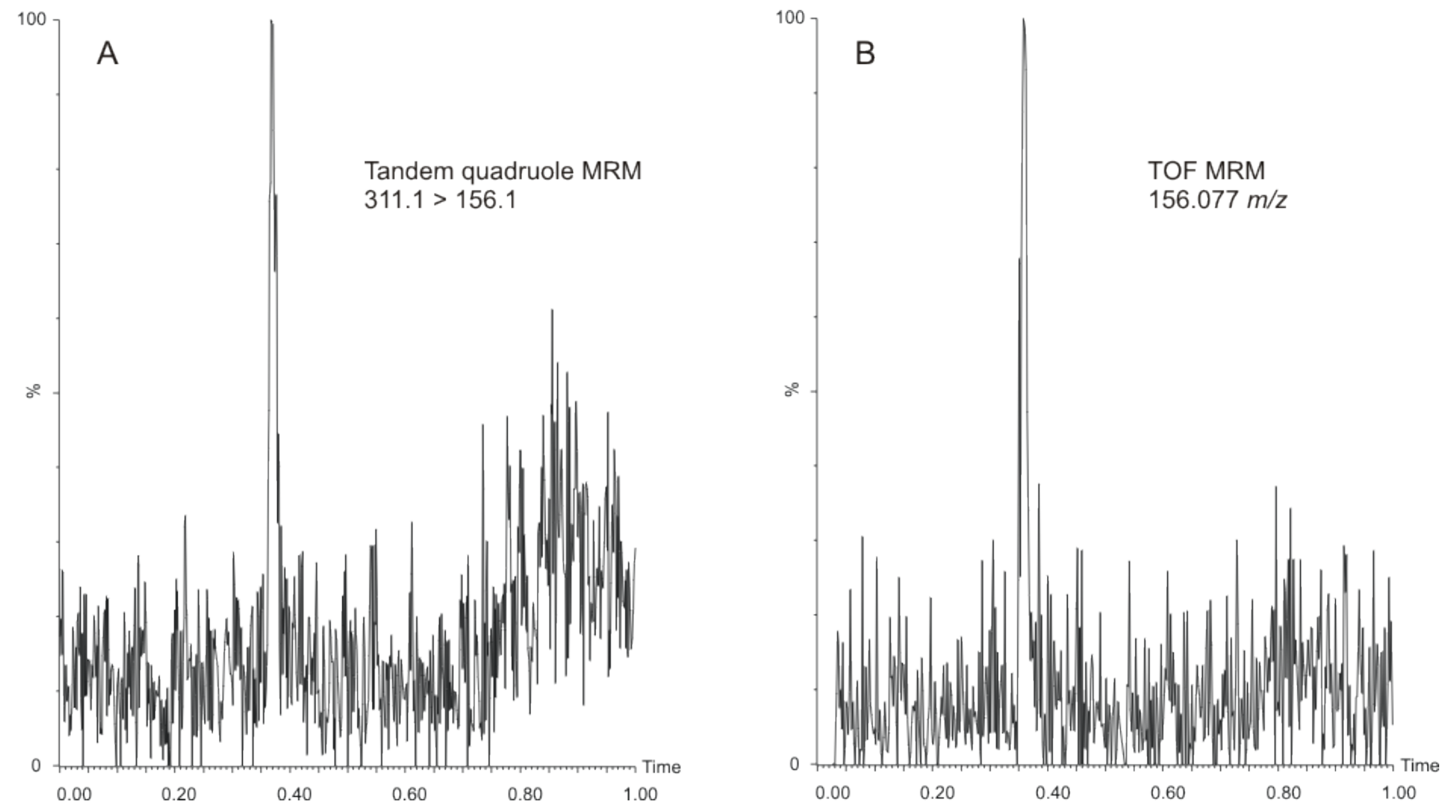

Figure S2. LLOQ MRM chromatograms for $5 \mathrm{fg}$ of sulfadimethoxine in absence of matrix injected on column. The left (A) pane illustrates the tandem quadrupole MRM chromatogram monitoring the $\mathrm{m} / \mathrm{z} 311.1>156.1$ transition using $0.7 \mathrm{FWHM}$ quadrupole resolution settings and the right (B) pan the high resolution TOF MRM equivalent isolating $\mathrm{m} / \mathrm{z} 311.1$ with $0.7 \mathrm{FWHM}$ quadrupole resolution and EDC TOF full scan MS/MS read out. The LLOQ was specified as the lowest concentration calibration point where the back calculated concentrations for all replicate injections were within $25 \%$ of the expected value. 
A
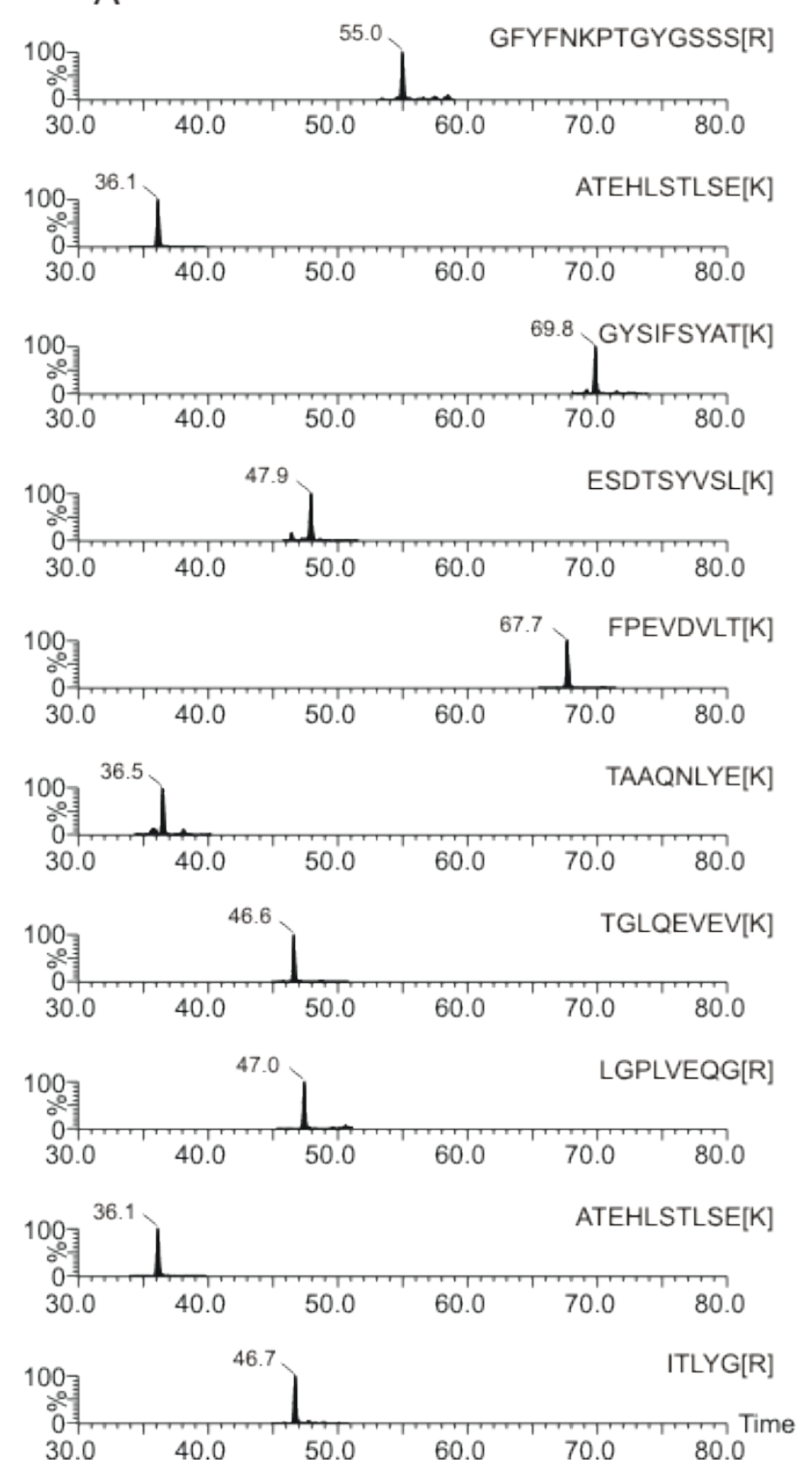

B
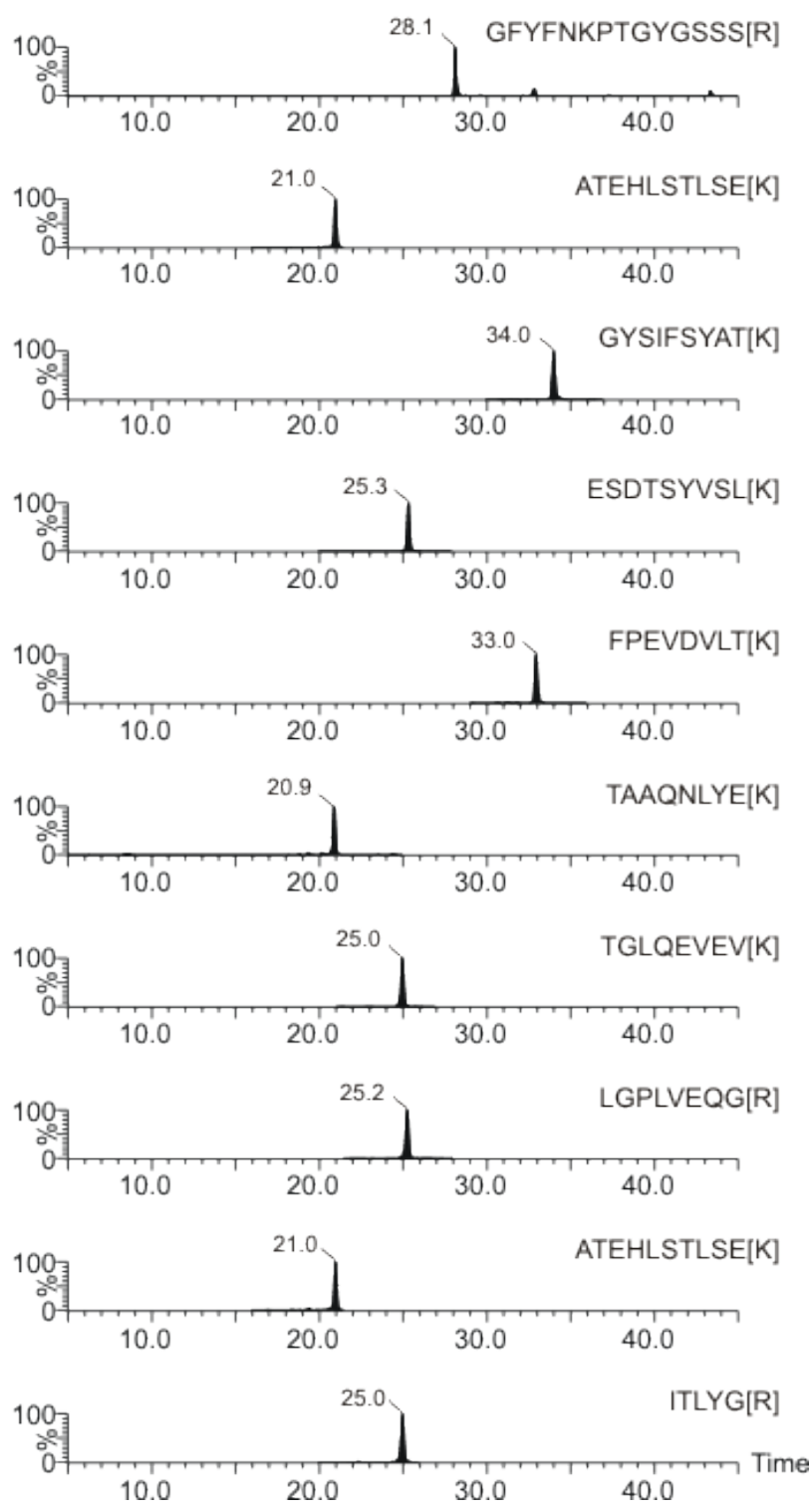

Figure S3. Example tandem quadrupole MRM chromatograms for ten SIL peptides injected 125 amol on-column using (A) 90 min reversed phase gradient nanoscale LC chromatography and (B) 45 min reversed phase gradient micro-fluidics. 

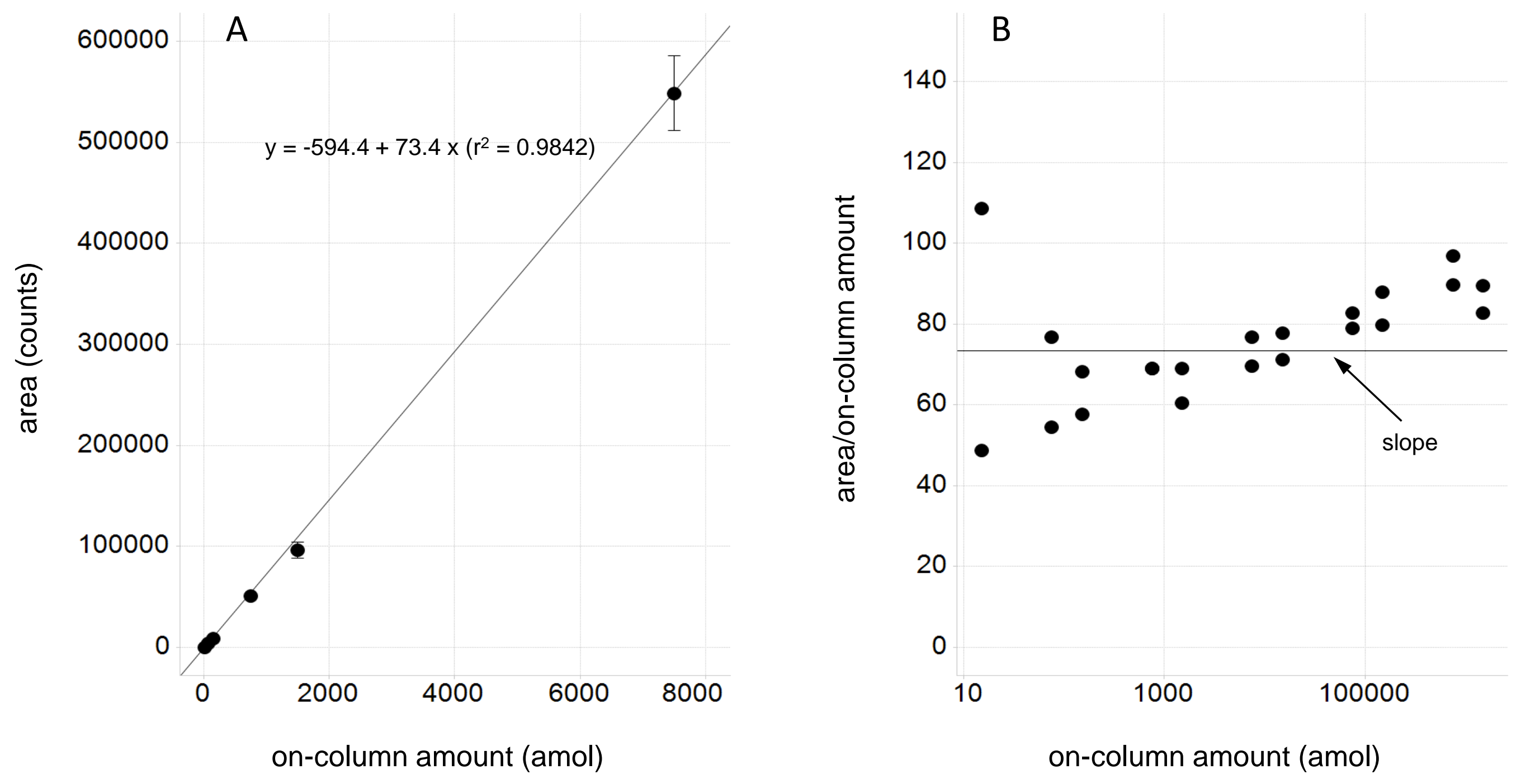

Figure S4. Calibration/quantitation curve for LGPLVEQGR- ${ }^{13} \mathrm{C}_{6}{ }^{15} \mathrm{~N}_{4}$ ranging from 15 amol to 1.5 nmol injected on-column using a $150 \mu \mathrm{m}$ id precolumn based micro-fluidics column configuration in combination with tandem quadrupole (Xevo TQ-S) MRM, illustrating (A) linearity for the lower orders of the investigated range and (B) linear response of the LC-MS system across the complete dynamic range. See section Experimental Conditions and Supplementary Table 1 for additional experimental and MRM details. 


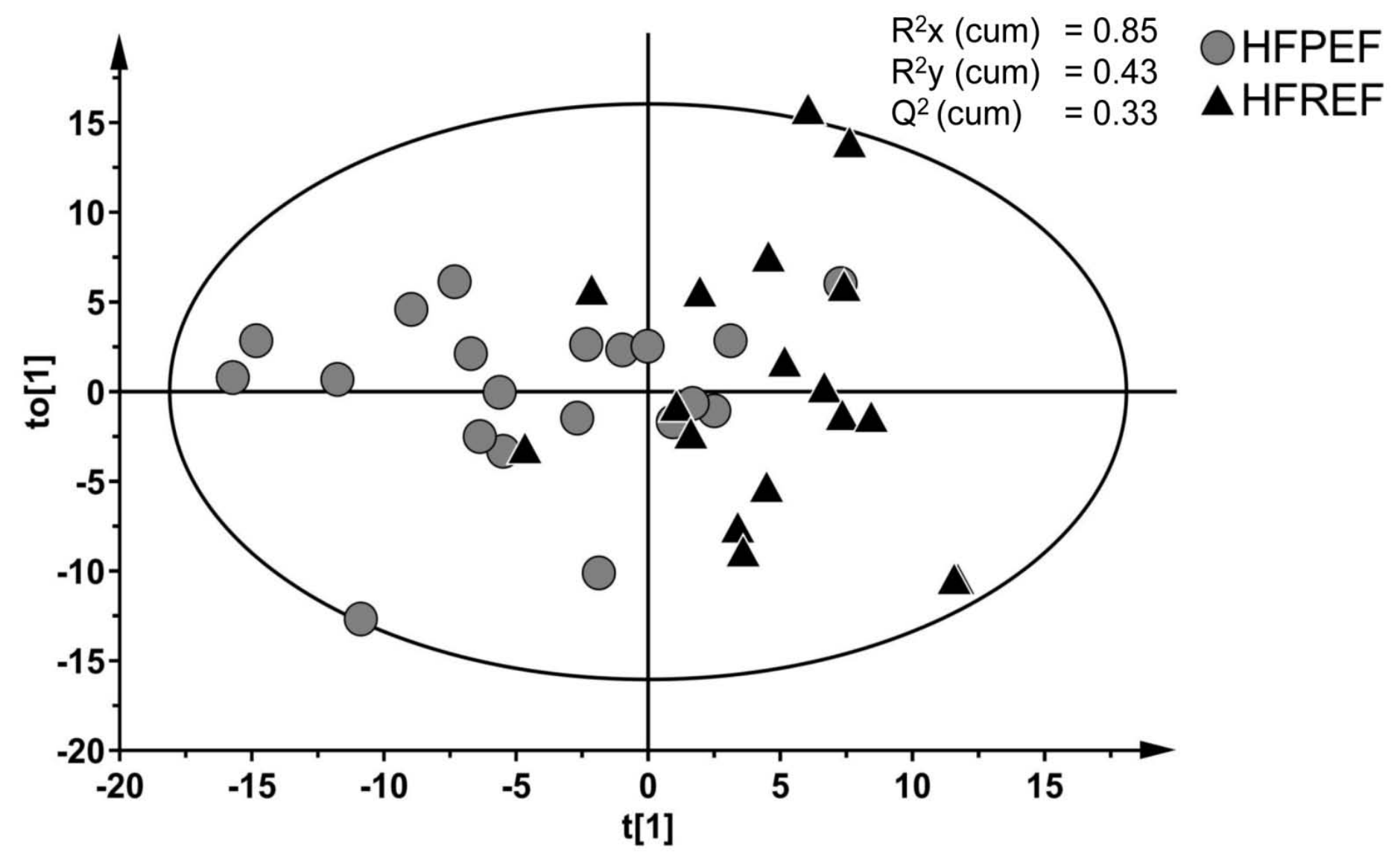

Figure S5. Multivariate OPLS-DA analysis showing the separation and classification of HFPEF and HFREF samples. Circles = HFPEF patient samples; triangles = HFREF patient samples. The model indicates that disease can be partially classified using a multiplex tandem quadrupole LC-MRM-MS based assay. 